Wayne State University

DigitalCommons@WayneState

English Faculty Research Publications

English

$8-1-2012$

\title{
Morphological Alternations at the Intonational Phrase Edge
}

Robert Henderson

Wayne State University, rhenderson@wayne.edu

\section{Recommended Citation}

Henderson, Robert. "Morphological Alternations at the Intonational Phrase Edge." Natural Language \& Linguistic Theory 30.3 (2012): 741-789. doi: 10.1007/s11049-012-9170-8

Available at: http://digitalcommons.wayne.edu/englishfrp/23

This Article is brought to you for free and open access by the English at DigitalCommons@WayneState. It has been accepted for inclusion in English Faculty Research Publications by an authorized administrator of DigitalCommons@WayneState. 
Noname manuscript No.

(will be inserted by the editor)

\title{
Morphological Alternations at the Intonational Phrase Edge \\ The Case of K'ichee'
}

\author{
Robert Henderson
}

Received: 6 November 2009 / Accepted: 11 December 2010

Keywords Syntax-Prosody Interface, Morphology, Prosody

Abstract This article develops an analysis of a pair of morphological alternations in K'ichee' (Mayan) that are conditioned at the right edge of intonational phrase boundaries. I propose a syntax-prosody mapping algorithm that derives intonational phrase boundaries from the surface syntax, and then argue that each alternation can be understood in terms of output optimization (Mascaró 2007; Mester 1994). The important fact is that K'ichee' requires a prominence peak rightmost in the intonational phrase, and so the morphological alternations occur in order to ensure an optimal host for this prominence peak. Finally, I consider the wider implications of the analysis for the architecture of the syntax-phonology interface, especially as it concerns late-insertion theories of morphology (Anderson 1982, 1992; Embick and Noyer 2001; Halle and Marantz 1993; Hayes 1990, among others). The primary result is that late lexical insertion must occur at least as late as the construction of intonational phrases.

\section{Introduction}

The principal concern for theories of the syntax-phonology interface is to determine what information from one module is available to the other. For instance, classic work in prosody shows that phonological rules do not reference syntax, but only appear to do so through prosody, which acts as an intermediary (Nespor and Vogel 1986; Selkirk 1980, 1984, among many others, though see Pak (2008) for a recent dissenting view). On the opposite side of the interface, Zwicky and Pullum (1988) conclude that the syntax proper has no access to phonological information.

Many modern theories of morphology make use of this picture, distributing various aspects of morphology across different sides of the interface. For example, Distributed Morphology (Halle and Marantz 1993; Embick and Noyer 2001, inter alia) separates the phonological contribution of morphemes from their featural contribution. In the syntax we have

Stevenson College

UC, Santa Cruz

1156 High Street

Santa Cruz, CA 95064

E-mail: rmh@ucsc.edu 
bundles of features and only in the phonological component do we finally insert phonological material. At this point we leave morpho-syntax and are on our way to morpho-phonology, where phonology can affect the placement and phonological form of morphemes. It is through this notion of transfer from one representation to another that derivational theories of the interface go one step further and ask, not just what information is available across an interface, but when that information is available.

Our theories present these questions, but their resolution is an empirical issue. Using clitic placement, many researchers have provided strong evidence that post-syntactic morpho-phonology needs access to levels of the prosodic hierachy up to the intonational phrase ( $\iota$-phrase) (Ackema and Neeleman 2003; Aissen 1992; Chung 2003; Hayes 1990; Inkelas 1990; Zec and Inkelas 1990). For instance, Aissen (1992) shows that the distribution of the deictic clitic un in Tzotzil is governed by $\iota$-phrases; specifically, un must be final in its $\iota$-phrase. What is not clear is what prosodically sensitive morphology of this sort says about the late insertion of vocabulary items. That is, we could easily imagine that these clitics appear in the syntax and only later move in the phonology to attach to an appropriate host.

Using original fieldwork from K'ichee', a Mayan language spoken by over a million people in highland Guatemala (Richards 2003), I provide strong phonological evidence for the late insertion of morphemes. ${ }^{1}$ Moreover, I show that lexical insertion comes at least as late as $\iota$-phrase construction. The crucial data come from a series of morphological alternations in K'ichee' that are conditioned at the edge of intonational phrases. The first involves a set of semantically vacuous verbal suffixes that are not realized phonologically unless they abut the $\iota$-phrase. The second case concerns certain clitics that take distinct forms at the end of the $\iota$-phrase. In both cases, we cannot choose which morpheme will appear until we have built intonational phrases because the choice is phonologically optimizing for the distribution of intonational phrase prominence peaks. Assuming a model where syntax feeds phonology, these morphemes must be disassociated from their phonological content in the syntax because it would not be possible to know what phonological forms they should take. This is precisely what late insertions theories of morphology would expect. ${ }^{2}$

The next section introduces K'ichee' and the morphological alternations analyzed in this work. Section 3 concerns the boundary that conditions these morphological alternations. I argue that it is a prosodic boundary and then show that it must be the intonational phrase. Section 4 shows that we can understand the relevant morphological alternations as phonologically optimizing when we take into account the fact that K'ichee' requires the peak prominence of the $\iota$-phrase to be aligned rightmost in the $\iota$-phrase. Section 5 concludes and considers areas for future research.

\footnotetext{
${ }^{1} \mathrm{~K}$ 'ichee' is not monolithic and the dialects can diverge greatly. The data for this paper come from two variants: Santa Cruz del Quiché and Santa Lucía Utatlán (where they speak a dialect close to that of Nahualá). The two dialects agree on all the data presented here, where testable. If the data are not testable in one dialect due to a missing morpheme or phonological phenomenon, I indicate this in the text.

${ }^{2}$ The disassociation of the featural and phonological contribution of morphemes, which we argue for here, is compatible with various models of the morpho-phonological component of the grammar. Focusing on prosodically conditioned allomorphy, it is compatible with global parallel approaches, like OT (Mascaró 2007; Mester 1994, among others), fully derivational treatments, like Embick (2010), as well as combinations of the two. We largely leave this fundamental question unanswered, though the analysis favors an OT approach due to the output optimizing effect of the alternations, which we will see.
} 


\section{Phrase-final morphological alternations}

K'ichee' has a set of morphemes that have been called phrase-final in the descriptive literature (Larsen 1988; Mondloch 1978). The name comes from the fact that they are morphemes or allomorphs that only appear at the end of some phrase. The goal of this work is to determine precisely which phrase is at issue and to understand why morphemes should be sensitive to this boundary. This section presents background information on K'ichee' and introduces the two types of phrase-final alternations that will be the focus of this work, specifically the status suffixes and CV/CVC clitic alternations.

K'ichee' has an ergative-absolutive agreement system with no case marking on nominals. As such, it is pro-drop and possesses only emphatic pronouns. When nominal arguments do appear, K'ichee' basic word order is VOS, although preverbal arguments are more common in texts since the preverbal space is used to indicate topic and focus (Larsen 1988; Mondloch 1978). Tense/Aspect/Mood (TAM) and other inflectional morphology are verbal prefixes, while derivational morphology is suffixed to the verb root. A large number of these verb roots are of the form CVC, and the language distinguishes these canonical root forms morphologically. In fact, the first phrase-final phenomenon to be considered involves the K'ichee' status suffixes, which distinguish between CVC root verbs and derived verbs.

\subsection{The status suffixes}

The status suffixes in K'ichee' indicate verb class membership, where classes are defined in terms of TAM, transitivity, and whether the verb is root or derived (Kaufman 1990; Can Pixabaj 2004, 2010; Larsen 1988; López Ixcoy 1997; Mondloch 1978). ${ }^{3}$ Figure 2.1 summarizes the distribution of these suffixes. Those that play a prominent role in this work are in boldface. $^{4}$

\begin{tabular}{|l|c|c|c|}
\hline & Root Transitive & Derived Transitive & Intransitive \\
\hline simple & $\mathbf{- o}$ & $-\mathrm{j}$ & $-\mathbf{i k}$ \\
\hline dependent & $-\mathrm{a}$ & $-\mathrm{j}$ & $-\mathrm{a} / \mathbf{- o q}$ \\
\hline perfect & $-\mathrm{Vm}$ & $-\mathrm{m}$ & $-\mathrm{inaq}$ \\
\hline
\end{tabular}

Fig. 1 K'ichee' Status Suffixes, adapted from Kaufman (1990)

Thus, a root transitive verb like chap in simple aspect, here completive, takes the $-o$ status suffix (1). In contrast a root intransitive verb in simple aspect takes the suffix $-i k(2){ }^{5}$

\section{(1) Xin-chap-o. \\ INFL-grab-SS \\ I grabbed it. \\ (2) Xin-war-ik. \\ INFL-sleep-SS}

\footnotetext{
${ }^{3}$ I leave out transitive verbs derived by the suffix $b$ ' $a$ ', which carry no status suffixes.

${ }^{4}$ Here simple is a cover term including both completive and incompletive aspects. Dependent TAM includes the imperative as well as a verb form that involves the incorporation of various movement particles into the verbal stem. Finally, the perfect class consists of the analogue of the English perfect.

${ }^{5} \mathrm{AP}=$ anti-passive, INF=infinitive, INFL=inflection, INSTR=instrumental, IRR=irrealis, NEG=negation, $\mathrm{PASS}=$ passive, $\mathrm{PL}=$ plural, $\mathrm{PRN}=$ pronoun, $\mathrm{PRT}=$ particle, $\mathrm{REP}=$ reportative, $\mathrm{SS}=$ status suffix
} 
I slept.

If the transitive verb root in (1) is passivized by lengthening the vowel, it becomes intransitive, and then it appears with the intransitive status suffix $-i k(3)$, just like the root intransitive war in (2). ${ }^{6}$

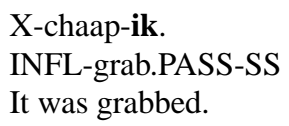

The contrast between (1) and (3) shows that the status suffixes do not change the transitivity of a predicate, they only reflect valency information already available from the lexical content of the predicate (1), or from a combination of lexical information and derivational morphology (3). This is a general property of the status suffixes; that is, while their distribution correlates with semantic properties like TAM and transitivity, they are generally not the only bearers of this information, which is represented elsewhere. ${ }^{7}$ This is particularly true for the status suffixes $-i k$ and $-o$, and as a result, speakers judge forms contrasting in the appearance of a status suffix to be synonymous. In what follows, I will treat $-i k$ and $-o$ as semantically vacuous. That being said, I do not consider them to be deficient in morphological features. They are specified in the lexicon for aspect, transitivity, and root class, which determines the set of verbs each status suffix can combine with.

The status suffixes $-i k$ and $-o$ are important to the discussion because of their phrasefinal distribution; that is, they do not appear phrase-medially, even when morphologically conditioned. This is in contrast to the the unbolded status suffixes in figure 2.1, which always appear when morphologically conditioned. Consider the following example with the root transitive status suffix $-o$. The suffix appears at the end of the utterance (4-a), but when the verb is phrase-medial (4-b), the suffix cannot appear. In the discussion that follows, I indicate those places where there is a missing status suffix with the symbol $-\otimes$.

$$
\begin{array}{ll}
\text { a. } & \text { Xu-tij-o. } \\
\text { INFL-eat-SS } \\
\text { He ate it. }
\end{array}
$$

b. Xu-tij- $\otimes$ le wah.

INFL-eat the tortilla

He ate the tortilla.

The same facts hold for the intransitive status suffix $-i k$.

$$
\begin{aligned}
& \text { a. } \quad \text { Xin-kos-ik. } \\
& \text { INFL-tire-SS }
\end{aligned}
$$

\footnotetext{
${ }^{6}$ Historically, passives of root transitive verbs were formed with an infixal [h], so chap would become chahp in the passive. An intermediate sound change eliminated this infixation by changing CVhC syllables into CVVC syllables (Campbell 1977). The result is that now passives of root transitives are indicated by vowel length.

${ }^{7}$ Some of the status suffixes are fused with aspectual information and are the sole bearers of this information, like the series of perfective status suffixes. There are also status suffixes, like $-j$, which are the sole bearers of important morphological information. A derived transitive verb without $-j$ would be indistinguishable from a root transitive verb, neutralizing the key morphological distinction. Crucially, these other suffixes do not have a phrase-final distribution; they always appear, which is probably due to these functional considerations. Since they always appear whenever the verbal complex has the requisite feature set, unlike $-i k$ and $-o$, this work does not focus on them.
} 
I am tired.

b. Xin-kos- $\otimes$ rumal nuchaak.

INFL-tire because my.work

I am tired because of my work.

That the status suffixes are semantically vacuous makes sense of the fact that they can disappear without loss of information, but a puzzle remains: what is their distribution, and why do they have that particular distribution? The rest of this work is dedicated to answering these two questions, and will show that the answer is, in both cases, prosodic.

\subsection{The clitic alternations}

The second type of phrase-final allomorphy to be considered concerns alternations between CV and CVC forms of certain clitics (Can Pixabaj 2010). An example of this phenomenon involves the irrealis clitic, which accompanies negation. ${ }^{8}$ Example (6) shows that when the clitic is at the end of the utterance, it appears in its CVC form, but phrase-medially, it takes a $\mathrm{CV}$ form.
a. Na xu-tij- $\triangle$ taj.
NEG INFL-eat IRR
He didn't eat it.

b. Na xu-tij- $\otimes$ ta le wah.

NEG INFL-eat IRR le wah

He didn't eat the tortilla.

Example (7) presents a similar contrast involving the polarity question clitic. Phrase-finally, it takes a CVC form $k^{\prime} u t$, while elsewhere it is $k^{\prime} u$ (Can Pixabaj 2010). ${ }^{9}$
a. La xu-tij- $\otimes$ k'ut.
Q INFL-eat Q
Did he eat it?
b. La xu-tij- $\bigotimes$ k'u le wah.
Q INFL-eat Q le wah
Did he eat the tortilla?

Once again the same two questions arise: (1) What is the domain of this phenomenon, and (2) why do we see the particular distribution that we do? That is, why CV forms phrasemedially and CVC forms phrase-finally? I argue that there are similar answers for both the clitic alternations and the status suffixes, but there is an important distinction between these two phenomena that I want to make clear before proceeding. The status suffixes are, in fact, verbal suffixes, while CV/CVC alternations occur only with clitics.

\footnotetext{
${ }^{8}$ The negative operator in K'ichee' varies across dialects. In most places it is Man, but it is Na in Nahualá and Santa Lucía Utatlán. I will move freely between these variants in the text depending on where the data come from.

${ }^{9}$ Not all dialects of K'ichee' have the polarity particle $k$ ' $u t$. It is preserved in the variant spoken in Nahualá and Santa Lucía Utatlán.
} 
Following the criteria established by Zwicky and Pullum (1983) and Zwicky (1985) we can establish that the irrealis particle ta/taj and the polarity question particle $k^{\prime} u / k^{\prime} u t$ are clitics. First, they exhibit a low degree of selection with respect to their hosts. They can attach to verbs (6), nouns (8), prepositions (9), or even functional particles like the focus particle (10) and auxiliaries (11). In the following examples, bold indicates the scope of the operator.

Man pa k'ayib'al ta xu-tij-o.
NEG in market IRR INFL-eat-SS

It wasn't in the market that he ate it.

Man ruk' ta ikaj xu-ch'ay-b'e-j.

NEG with IRR axe INFL-cut-INSTR-SS

It wasn't with the axe that he cut it.

(10) Man aree ta ri a Xwan X-el-ik.

NEG FOC IRR the CLF Juan INFL-leave-SS

It wasn't Juan who left.

(11) Man tajin ta kin-chakun-ik.

NEG PROG IRR INFL-work-SS

I am not working.

The examples above indicate another property that argues for their analysis as clitics, namely: they are prosodically deficient. Notice that while the clitic skips over the preposition $p a$, it can attach to other functional morphemes, like aree (10) and ruuk' (9). The generalization is that these morphemes attach to the right of the first prosodic word in the domain they operate over, where prosodic words are larger than a single light syllable. The fact that they need a prosodic host, while disregarding its formal category, is strong evidence that they are clitics.

The status suffixes, in contrast, behave differently in these respects, supporting their analysis as affixes. First, they occur exclusively with verbs. More than that, specific instances of this class of morphemes only occur with tightly constrained subclasses of verbs. Their distribution is therefore much more restricted than those elements identified as clitics. Another argument that the status suffixes are suffixes is that there are unpredictable gaps in the verbal paradigm they belong to. For example, derived transitive verbs derived by $b$ ' $a$ ' have no status suffix in either aspect class, but there are no such holes for other derived transitives. Zwicky (1985) notes that unpredicatable morphological gaps are indicative of affixes, which are tied more closely to the idiosyncracies of their hosts than clitics.

The data support the initial characterization given for these two classes of morphemes. The status suffixes are verbal affixes, while the morphemes that undergo CV/CVC alternations phrase-finally are clitics. Though they differ in this respect, both classes of morphemes participate in phrase-final morphological alternations. The puzzle is to understand which boundary these alternations take place at, and what mechanism interacts with the boundary to produce the resulting pattern. The next section considers the first of these two questions. 


\section{Phrase-finality and syntax-prosody mapping}

Understanding the phrase-final behavior of the alternations just introduced requires us to unpack the meaning of phrase-finality. The relevant boundary could be either syntactic or prosodic, and could correspond to one of many levels in the hierarchy. I argue that the generalization must be made over prosody and that the phrase-final morphs occur only when they are final in the intonational phrase. With these results in hand, we can use the phrase-final morphs to show how K'ichee' parses syntactic structure into high level prosodic structure, which will result in a set of syntax-prosody mapping constraints to derive the distribution of intonational phrase boundaries.

\subsection{The distribution of phrase-final morphs: a prosodic account}

The status suffixes and phrase-final clitic allomorphs have the same distribution. In every structural configuration where one is conditioned, the other must appear when placed in the same context. Therefore, I will use the two phenomena interchangably as boundary diagnostics. Although I will finally settle on a prosodic account of the distribution of the phrase-final morphological alternations, it is important to also understand their syntactic distribution because we will need a syntax-prosody mapping algorithm to derive the relevant prosodic boundaries. Thus, after showing that the distribution of the phrase-final morphs correlates with clausehood, I will detail my syntactic assumptions about multiclausal structures in order to see their syntactic distribution more clearly. What we will find is that syntax is almost but not quite adequate for stating the distribution of the phrase-final morphological alternations. But this is precisely what we would expect to find if they have a prosodic distribution and there is only a rough correspondence between syntax and prosody. Using this insight, I then give a syntax-prosody mapping algorithm that makes it possible to give a simple prosodic generalization about the distribution of the phrase-final morphological alternations, and which is both theoretically and emipirically superior to a syntactic account.

We have already seen that the phrase-final morphs occur at the end of the utterance, but this is only because the end of an utterance corresponds to a clause boundary. We can find multiple such morphemes in an utterance and find them utterance medially when there are multiple clauses in the utterance (12).

a. Xinw-il-o chi xwa'-ik.

INFL-see-SS that he.ate-SS

I saw that the boy ate.

b. Ri ja' ri xin-tij-o xub'an-o.

the water PRT INFL-eat-SS it.did.it-SS

The water that I drank did it.

c. Xin-chap-o su xu-loq'-o.

INFL-grab-SS what INFL-buy-SS

I grabbed what he bought.

d. Xin-kos-ik rumal xin-chakun-ik. INFL-tire-SS because INFL-worked-SS I am tired because I worked. 
Each example in (12) contains multiple phrase-final morphs. The unifying feature of all of these examples is that there are multiple clauses as well. I want to consider the syntax of each of these constructions in turn, which will help determine what feature of clausehood conditions the appearance of the phrase-final morphs. Specifically, we will see that the phrase-final morphs correlate with the distribution of CP boundaries in the syntax.

I assume a general clausal syntax for K'ichee' in line with that proposed by Aissen (1992, 1996) for Mayan in general, and the closely related language Tz'utujiil in particular. An important feature is that the specifiers of lexical projections are to the right, while functional projections have specifiers to the left. This means that the subject originates in a rightward facing specifier (and can remain in situ), but there are topic and focus positions in the rightward branching left periphery that can host displaced constituents like the subject. Finally, I will assume that interrogative phrases move to the specifier of CP.

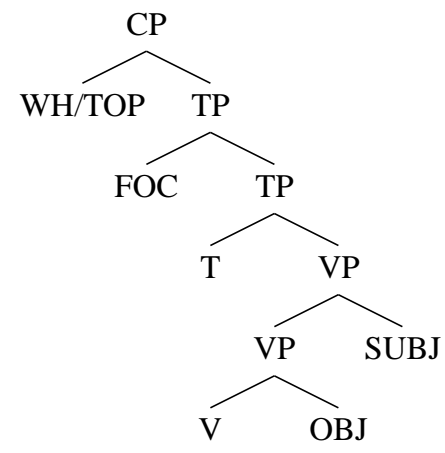

First, consider the behavior of the phrase-final morphs in a simple intransitive clause. Recall that the phrase-final morphs appear if they are final in the clause. In syntactic terms, the phrase-final morphs appear if and only if they are the last overt element in the CP. For example, the simple intransitive status suffix does not appear in (14) because the post-verbal subject intervenes between where it would appear and the right edge of the CP.

Xe'-ul- $\otimes \quad$ le alah chi'lle alih.

INFL-arrive the boy and the girl

The boy and the girl arrived.

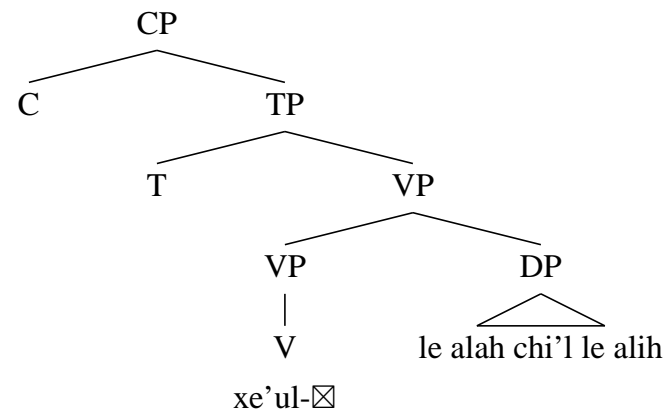

If there is a pro-drop subject like in (16), the status suffix must appear, which can be attributed to its ability to be the last overt element in the CP. 
(16)

Xe'-ul-ik.

INFL-arrive-SS

They arrived.

(17)

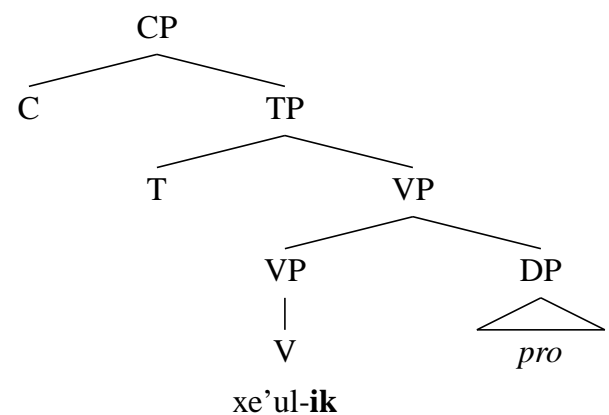

This idea immediately extends to cases where there are phrase-final morphs in directly preverbal position due to clausal adjuncts (18). Example (18-a) contains a CP headed by the conditional complementizer we, while example (18-b) has the complementizer aree taq. ${ }^{10}$ In each case, phrase-final morphs must appear if they are rightmost in the adjunct $\mathrm{CP}$.

a. We kin-kos-ik kin-war-ik.

if INFL-tire-SS INFL-sleep-SS

If I get tired, I sleep.

b. Aree taq kin-kos-ik kin-war-ik.

when INFL-tired-SS INFL-sleep-SS

When I get tired, I sleep.

(19)

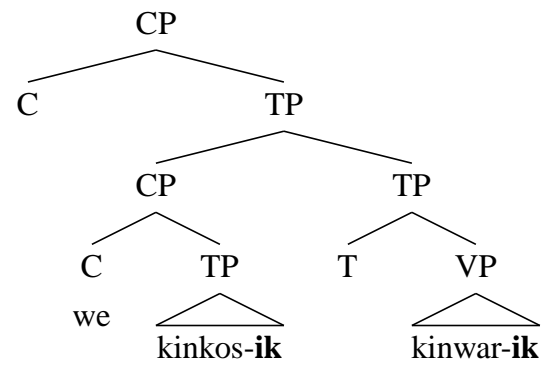

The right edge of the $\mathrm{CP}$ is at issue in these examples, and not the left edge of the TP/VP, because phrase-final clitic forms cannot appear preverbally without a containing clause.

a. Na iwir ta $\left(_{T P / V P} \mathrm{xr}-\mathrm{il}-\otimes\right.$ le k'amol b'e).

NEG yesterday IRR INFL-see the leader

It wasn't yesterday that he saw the leader.

\footnotetext{
${ }^{10}$ Following Larsen (1988), I take aree taq to be a complementizer. One of its constituents is aree, which is the focus operator and which can be argued to sit in $\mathrm{C}^{\circ}$. Also, Mayan languages have only one (or two) uninflected preposition and it is always locative, so I would not want to propose another without strong evidence.
} 
b. *Na iwir taj $(T P / V P$ xr-il- $\triangle$ le k'amol b'e).

NEG yesterday IRR INFL-see the leader

It wasn't yesterday that he saw the leader.

a. La iwir k’u $(T P / V P$ xr-il- $\otimes \quad$ le k'amol b'e $)$.

$Q$ yesterday $Q \quad$ INFL-see the leader

It wasn't yesterday that he saw the leader.

b. *La iwir k'ut $\left(_{T P / V P} \mathrm{xr}-\mathrm{il}-\otimes \quad\right.$ le k'amol b'e).

$Q$ yesterday $Q \quad$ INFL-see the leader

It wasn't yesterday that he saw the leader.

The examples in (20)-(21) contrast with those in (18). When there is a CP boundary before the TP/VP, the phrase-final morphemes appear, but they cannot appear in the focus negation or polarity question structures in (21). Since the subsequent material is the same in both cases, we can implicate the right edge of the $\mathrm{CP}$ in the distribution of phrase-final morphs.

Just as phrase-final morphs appear utterance medially when a clause precedes the matrix verb phrase, they also appear in the matrix clause when there are post-verbal embedded clauses. For example, nominal direct objects block the appearance of phrase-final status suffixes (22), but clausal complements do not (23).
Xinw-il- $\otimes$ le alah.
INFL-see the boy
I saw the boy.
Xinw-il-o chi xwa'- $\otimes$ ri alah.
INFL-see-SS that he.ate the boy
I saw that the boy ate.

Taking a close look at the syntax of complementation, the contrast between (22) and (23) can be attributed to the left edge of the $\mathrm{CP}$ contributed by the finite complement clause. Complement clauses originate as object complements to $\mathrm{V}^{\circ}$ under selection and trigger third person singular absolutive agreement on the verb (24).

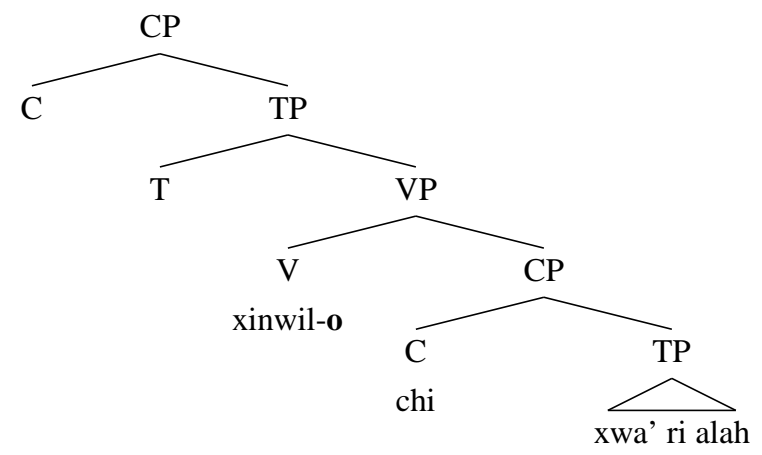

That being said, complement clauses do not always remain in situ. If there is any other post-verbal material, the complement clause must extrapose over it. Example (25) shows this with a post-verbal subject, while example (26) shows the same with a temporal adjunct. 
a. Xr-il- $\otimes$ ri a Xwan chi $x-w a '-\otimes$ ri alah. INFL-see the CLF Juan that INFL-eat the boy Juan saw that the boy ate.

b. *Xr-il- $\otimes$ chi $\mathrm{x}$-wa'- $\triangle$ ri alah ri a Xwan. INFL-see that INFL-eat the boy the CLF Juan Juan saw that the boy ate.

a. Xin-b'ij iwir chi xe-b'e- $\triangle$ pa Armita.

INFL-say yesterday that INFL-go to Guatemala City Yesterday I said that they went to Guatemala City.

b. Xin-b'ij chi xe-b'e- $\triangle$ pa Armita iwir. INFL-say that INFL-go to Guatemala City yesterday *Yesterday I said that they went to Guatemala City. (under this reading)

It is unclear whether complement clauses extrapose when there is no other post-verbal material to make it apparent. But whether or not extraposition occurs, the status suffix appears on the matrix predicate when it is the last element before the left edge of the $\mathrm{CP}(24)$. When the $\mathrm{CP}$ visibly extraposes, the status suffix cannot appear, which can be attributed to the intervening constituents.

Xr-il- $\triangle \quad$ ri a $\quad$ Xwan chi $\mathrm{x}-\mathrm{wa}^{\prime}-\otimes$ ri alah.

INFL-see the CLF Juan that INFL-eat the boy

Juan saw that the boy ate.

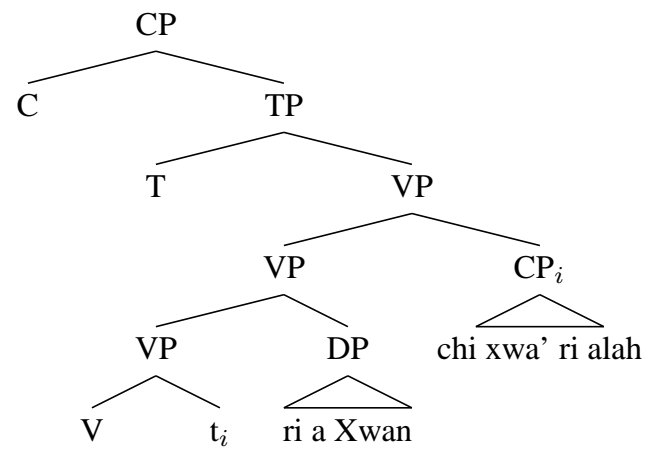

xril- $\otimes$

A second argument that the phrase-final morphs are sensitive to the left edge of the CP in finite complement clauses is that the phrase-final morphs cannot appear with non-finite complements (29). ${ }^{11}$

a. Xki-chap- $\triangle$ toj-on-ik.

INFL-start pay-AP-INF

They started to pay.

\footnotetext{
${ }^{11}$ One class of non-finite predicates in K'ichee' carries the suffix - $i k$. It is distinct from the simple intransitive status suffix $-i k$, which I will continue to indicate with boldface. The infinitive suffix $-i k$ is not a phrase-final suffix and so it always appears.
} 
b. *Xki-chap-o toj-on-ik.

INFL-start-SS pay-AP-INF

They started to pay.

c. Xqa-chap- $\otimes$ ki-kuna-X-ik.

INFL-start their-cure-PAS-INF

We started to cure them (lit. their being cured).

d. *Xqa-chap-o ki-kuna-X-ik.

INFL-start-SS their-cure-PAS-INF

We started to cure them (lit. their being cured).

The contrast between finite and non-finite complements is predicted because non-finite complements do not constitute full CPs. We know this because they lack the positions in the left periphery for phrasal arguments to move into, for example, the focus position (30). Assuming that focused phrases move into the specifier of TP (Aissen 1992), we can conclude that non-finite clauses contain no TP, which is supported by the fact that they carry no tense/aspect morphology. Since non-finite complements lack the higher functional layer of the clause, we can take them to consist of a bare nominalized VP (32).

*Xqa-chap- $\otimes$ aree ri alitaab' ki-kuna-X-ik.

INFL-start FOC the girls they-cure-PAS-INF

We started to cure the GIRLS.

Xki-chap- $\bigotimes$ toj-on-ik.

INFL-start pay-AP-INF

They started to pay.

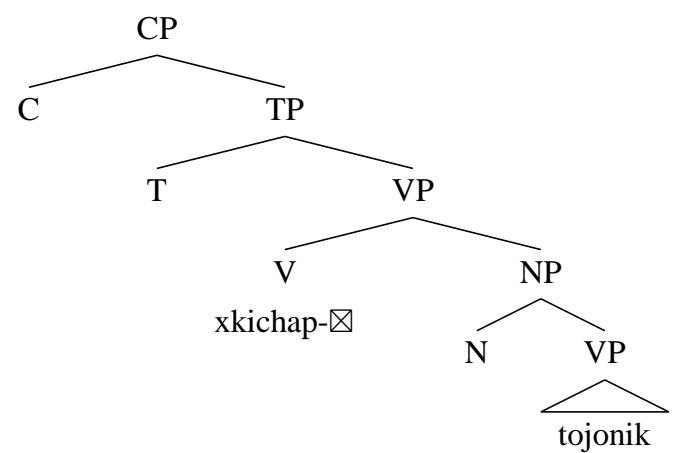

Since non-finite complements contain no $\mathrm{CP}$, there is no $\mathrm{CP}$ boundary to trigger the appearance of phrase-final morphs on the matrix $\mathrm{V}^{\circ}(31)$.

Another contrast showing importance of the left edge of CP boundaries for the distribution of phrase-final morphs is the contrast between headed relative clauses and headless WH-relatives.

a. Xu-chap- $\otimes$ ri b'ah ri $\quad$ xu-tij- $\otimes$ qa-kinaq.

INFL-catch the gopher PRN INFL-eat our-beans 
He caught the gopher that ate our beans.

b. *Xu-chap-o ri b'ah ri xu-tij- $\otimes$ qa-kinaq. INFL-catch-SS the gopher PRN INFL-eat our-beans He caught the gopher that ate our beans.

(34)

a. Xin-chap-o su xu-loq'-o.

INFL-grab-SS what INFL-buy-SS

I grabbed what he bought.

b. *Xin-chap- $\triangle$ su $\quad$ xuloq'-o.

INFL-grab what INFL-buy-SS

I grabbed what he bought.

phrase-final morphs cannot appear before headed relative clauses (33), but they must appear before headless WH-relatives (34). I assume that relative clauses adjoin to NP and there is operator movement to the specifier of $\mathrm{CP}$ in the relative clause (36). The crucial difference with headless WH-relatives is that the head is empty and the operator is overt (38).

Xu-chap- $\otimes$ ri b'ah ri $\quad$ xu-tij- $\otimes$ qa-kinaq.

INFL-catch the gopher PRN INFL-eat our-beans

He caught the gopher that ate our beans.

(36)

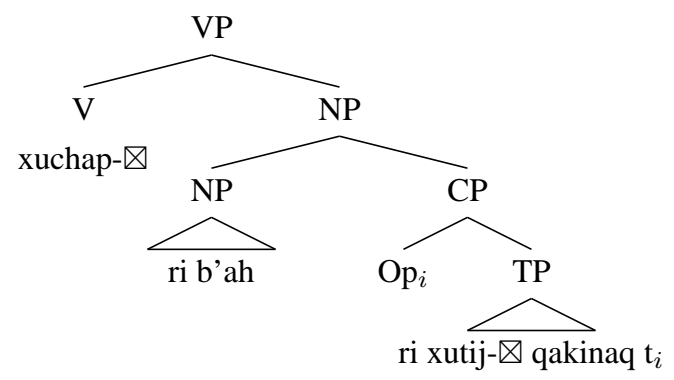

Xin-chap-o su xu-loq'-o.

INFL-grab-SS what INFL-buy-SS

I grabbed what he bought.

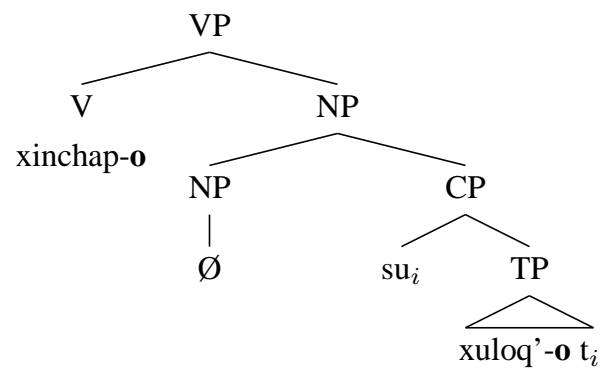

Notice that in (38), no overt material intervenes between the relative clause CP and the matrix predicate, while the head of the relative intervenes in (36). Once again, phonological adjacency to the left edge of the embedded $\mathrm{CP}$ correlates with the appearance of phrase-final 
morphs, not tree adjacency. Only intervening phonologically realized non-clausal material has a blocking effect.

Thus far we have been able to characterize the distribution of the phrase-final morphs in terms of adjacency to $\mathrm{CP}$ boundaries, but there is one counterexample to this straightforward generalization. Consider example (39), which contains a reason adjunct.

$$
\begin{aligned}
& \text { Xi-kikot aw-umaal. } \\
& \text { INFL-happy } 2 \text { sg-because } \\
& \text { I am happy because of you. }
\end{aligned}
$$

Reason adjuncts are built with what are called relational nouns in the literature on Mayan. Essentially, these are inflected prepositions that agree with their complements (39), in this case the second person singular. Notice that when the relational noun -umaal takes a NP complement, phrase-final morphology does not surface (40). The pattern changes when the relational noun takes a clausal complement, in which case, phrase-final morphology is obligatory (41).

a. Xin-kos- $\triangle$ r-umal nu-chaak.

INFL-tire 3sg-because my-work

I am tired because of my work.

b. *Xin-kos-ik r-umal nu-chaak.

INFL-tire-SS 3sg-because my-work

I am tired because of my work.

a. Xin-kos-ik r-umal xin-chakun-ik.

INFL-tire-SS 3sg-because INFL-work-SS

I am tired because I worked.

b. *Xin-kos- $\otimes$ r-umal $\quad$ xin-chakun-ik.

INFL-tire 3sg-because INFL-work-SS

I am tired because I worked.

Although we have seen similar cases where the addition of a clause triggers the appearance of phrase-final morphology, this case is special because the relational noun does not block the appearance of phrase-final morphs, even though it is not inside the CP that conditions their appearance (43). ${ }^{12}$

\section{Xin-kos-ik r-umal xin-chakun-ik. \\ INFL-tire-SS 3sg-because INFL-work-SS \\ I am tired because I worked.}

\footnotetext{
${ }^{12}$ We might worry that, despite appearances, -umaal has a different syntax when taking a clausal argument. For instance, if it were a complementizer, there would be no syntax-prosody mismatch. There are two arguments against this position, both of which are based on structural uniformities. First, both of the langauge's two locative preposition are also complementizers, namely chi for finite clauses and $p a$ with certain non-finite clauses. Crucially, neither of these cross-categorial complementizers shows agreement morphology like the relational noun -umaal. In fact, no unambiguous instance of $\mathrm{C}^{\circ}$ in the language agrees with the clause it embeds. Second, reason questions involve pied-piping with inversion (Aissen 1996; Coon 2009), which is a property of questioned possessive DPs and relational noun phrases alone. Questioning other clausal argument positions involve specific constituent question words, not pied-piping with inversion. In all these ways, -umaal behaves like a relational noun heading its own case assigning projection, triggering agreement, not an instance of $\mathrm{C}^{\circ}$.
} 
(43)

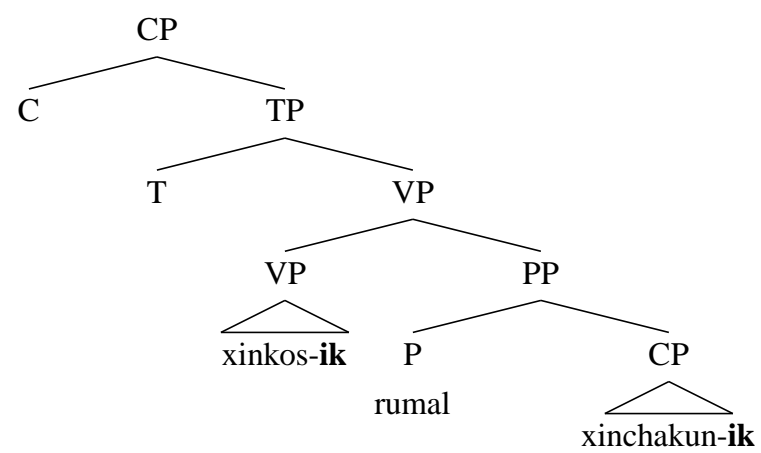

The result is that we cannot completely characterize the distribution of the phrase-final morphs in terms of adjacency to CP boundaries. We must include the caveat that the calculation of adjacency ignores intervening functional heads that take the conditioning $\mathrm{CP}$ as an argument. Although this is an unwelcome addition, examples like (43), still support the close connection between the distribution of $\mathrm{CP}$ boundaries and phrase-final morphology. Only with the addition of a clausal complement does the phrase-final morphology appear preceding reason adjuncts (41), even though there is the same type of adjunct of equal prosodic weight in (40). While there is a correlation between CPs and the distribution of phrase-final morphological alternations, the correspondence is rough. They track both the right and left edges of CPs, yet there are exceptions. In the next section I propose a prosodic account that captures the connection between CPs and phrase-final morphology, while eliminating the problems with the syntactic characterization.

\subsection{The prosodic alternative}

Although there is a correlation between the distribution of CP boundaries and phrase-final morphs, there are drawbacks to characterizing the distribution in terms of CPs. This section reconsiders the data just discussed and proposes that phrase-final morphological alternations are actually sensitive to intonational phrase boundaries. We will see that the correlation between CP boundaries and phrase-final morphology is actually due to the way syntax is mapped to prosody at the interface. This prosodic approach will not only solve the problems with the syntactic account, but it will also prove to be conceptually superior with respect to how syntax and prosody interact across the interface.

The first argument in favor of stating the distribution of status suffixes and phrase-final clitic allomorphs in terms of intonational phrases is that the result is simpler. We saw that status suffixes appear at both the right and left edges of CPs, as schematized in (44).

$$
\begin{array}{ll}
\text { a. } & (\mathrm{V}-\mathbf{i k})_{C P} \\
\text { b. } & \left(\mathrm{V}-\mathbf{o}(\text { finite clause-o })_{C P}\right)_{C P}
\end{array}
$$

This means that we cannot state the distribution of the phrase-final morphs in terms of CP finality, and instead have to characterize their placement disjunctively. If the generalization is made over prosodic structure, though, we can say that status suffixes and CVC clitic allomorphs appear at the end of intonational phrases. The reason is that independently motivated prosodic principles like STRICT LAYERING force the syntax-prosody mapping to return a flatter prosodic structuring from a recursive syntax (Selkirk 1980, 1984). For exam- 
ple, assuming a correspondence between CPs and intonational phrases, we get the following prosodic structures for the same syntactic structures in (44).

$$
\begin{aligned}
& \text { a. }(\mathrm{V}-\mathbf{i k})_{\iota-\text { phrase }} \\
& \text { b. (V-o })_{\iota-\text { phrase }}(\text { finite complement-o })_{\iota-\text { phrase }}
\end{aligned}
$$

Once we move to prosodic structure, the phrase-final character of the status suffixes and clitic allomorphy becomes apparent. The generalization is that they appear at the end of $\iota$-phrases.

Phrase-final morphemes appear iff they are final in the intonational phrase.

Moving to a prosodic characterization of the distribution of the phrase-final morphs allows the generalization to be stated in terms of phrase-finality, but it also presents a way to account for facts that made the syntactic generalization unappealing. Remember that the phrasefinal morphemes do not always surface directly adjacent to CP boundaries. Consider the following contrast repeated from above (47).

a. Xin-kos-ik rumal xin-chakun-ik.

INFL-tire-SS because INFL-worked-SS

I am tired because I worked.

b. *Xin-kos- $\otimes$ rumal xin-chakun-ik.

INFL-tire because INFL-work-SS

I am tired because I worked.

To account for the facts in (47), it was necessary to say that the phrase-final morphs could appear if the only element intervening between them and the onset of the CP was a functional head selecting the $\mathrm{CP}$ as a complement. This is a peculiar syntactic generalization, especially if we want to think of the phrase-final morphs as selecting for a syntactic constituent. The reason is that syntactic selection (subcategorization), in virtue of being a relation between sisters (Chomsky 1965; Grimshaw 1979, 1981), is not sensitive to the syntactic category of the complement of a head it selects for. By moving to a prosodic account, there is the possibility of solving the problem in a principled way. Although prosody tracks gross syntactic structure, there are many cases of syntax-prosody mismatches (see Nespor and Vogel (1986) and Chomsky and Halle (1968) for early examples), and so under a prosodic account it is not surprising that there should be examples like (47). ${ }^{13}$ In section 3.2.2 I argue that this particular mismatch is due to a preference for functor-argument pairs to be prosodified together, which is an explanation in the spirit of the SENSE UNIT CONDITION (Selkirk 1984). While I present the analysis later, the important point is that characterizing the distribution of the phrase-final morphs in prosodic terms allows us to connect their distribution to CPs in the syntax, while still accounting for mismatches that arise.

The final argument that we should treat phrase-final allomorphs in terms of prosody is conceptual. There is a long history of work in both syntax and phonology showing that the two components interact only through prosodic structure (Nespor and Vogel 1986; Selkirk 1980, 1984, 1995; Zwicky and Pullum 1988, among many others). Although it is still up

\footnotetext{
${ }^{13}$ A reviewer notes that the mismatches in Chomsky and Halle (1968) and Nespor and Vogel (1986) are cases where prosodic constituents are not syntactic constituents. While the K'ichee' case is not of this sort, it is similar in that the observed prosody fails to conform to a syntactic generalization that holds elsewhere in the language. The non-constituent cases are an extreme version of this, where no satisfactory syntactic generalization is available.
} 
for debate whether phonology impinges on syntax (see Zec and Inkelas (1990) and Anttila (2008) for arguments to the affirmative), it is generally accepted that phonology is sensitive to syntax only through prosodic structure, which acts as an intermediary (though see Hayes (1990) for a limited mechanism by which phonology can have access to richer syntactic information) ${ }^{14}$ If phrase-final morphology is phonologically optimizing, as I show in section 4 , then in choosing to characterize the distribution of phrase-final morphs in terms of syntax, we either miss generalizations about the role of clitic selection in reducing phonological markedness or we are forced to give low-level phonological processes like stress placement direct access to the syntax. Since we want to avoid both of these consequences, we should prefer prosodic accounts of the distribution of phrase-final morphs.

Even though the appearance of status suffixes and CVC clitic allomorphs seems to correlate with the distribution of $\mathrm{CP}$-sized constituents, we have seen that there are good arguments for taking the appearance of phrase-final morphs to be conditioned by a prosodic boundary. The reason why these morphs occur near CPs is that the intonational phrase is the prosodic boundary at issue, and in K'ichee', intonational phrases correspond roughly to CPs. In section 3.2.2 I provide an analysis of the K'ichee' syntax-prosody interface that correctly derives the distribution of $\iota$-phrase boundaries that we have seen here, which will then permit an account of the distribution of phrase-final morphology in terms of phonological optimization. Before doing this, though, I want to support the claim that it is intonational phrases that condition the appearance of phrase-final morphs, and not some other prosodic constituent.

\subsubsection{Which prosodic boundary?}

Although the distribution of the phrase-final morphs is best stated over prosody, we still do not know exactly which level in the prosodic hierarchy is at issue. After stating my assumptions about prosody, I will argue that the intonational phrase conditions the appearance of the phrase-final morphs. The form of the argument is to give upper and lower bounds in the prosodic hierarchy for the phrase-final phenomena, at which point we will be left with a single candidate: the intonational phrase.

In what follows, I will assume classic prosodic hierarchy theory (Selkirk 1980, 1984, 1995), which provides a universal hierarchy of prosodic constituents (48) and principles for how higher prosodic categories are built from lower ones.
a. Utterance
b. Intonational phrase
c. Phonological phrase
d. Prosodic word

The accompanying principles are that the phonological string is completely parsed into prosodic structure (EXHAUSTIVITY), and each prosodic constituent $i$ is immediately dominated by a prosodic constituent of type $i+1$ (STRICT LAYERING). While recent work has challanged these ideas, arguing that there are recursive prosodic structures (Truckenbrodt 1999; Wagner 2005; Ito and Mester 2006), there is no evidence that K'ichee' has recursive prosody at the levels of the hierarchy I consider here. Therefore, I will assume that the constraints enforcing STRICT LAYERING are ranked high in K'ichee'.

\footnotetext{
${ }^{14}$ Though here we are mostly concerned with whether phonology has access to syntactic phrase structure, a reviewer notes that English stress rules must have access to the cateogry label of a lexical item, which is a type of syntactic information (Chomsky and Halle (1968) among many others).
} 
We have already seen that the phrase-final morphs can occur phrase-medially, which shows that they are not triggered by the ends of utterances. ${ }^{15}$ To zero in on the intonational phrase, then, we only need to show that there are phonological phenomena that are sensitive to the level of the phonological phrase and that the phrase-final morphs are not sensitive to this smaller boundary. K'ichee' has such a process in the form of FINAL LARYNGEAL STRENGTHENING (AnderBois 2008). AnderBois (2008) notices that crosslinguistically there is pressure for the right edges of prosodic constituents above the foot to bear laryngeal features. This preference is expressed in some languages by aspirating final stops (Yukatek Maya, Klamath, Kashmiri, Yapese, Hupa, Sierra Popoluca), in others by debuccalization preserving laryngeal features (Yukatek Maya), and in still others by the epenthesis of [h] or [?] at the end of certain prosodic constituents (Yukatek Maya, Afar, Japanese, Dagbaani, Koasti, Kagoshima Japanese) (see AnderBois (2008) for the relevant references). K'ichee' falls into the last class, where open syllables at the end of phonological phrases must undergo [h] epenthesis. The relevant data are in (49)-(51). First note the contrast between (49-a) and (49-b). When the adjective $k^{\prime} i$ "a lot/much" is at the end of the utterance it surfaces with a final $[\mathrm{h}]$. When it modifies a following noun, the $[\mathrm{h}]$ phoneme disappears.

$$
\begin{aligned}
& \text { a. Xin-loq'- } \triangle \text { k'ih. } \\
& \text { INFL-buy a lot } \\
& \text { I bought a lot. } \\
& \text { b. Xin-loq'- } \triangle \text { k'i wah. } \\
& \text { INFL-buy a lot tortilla } \\
& \text { I bought a lot of tortillas. }
\end{aligned}
$$

Presumably there is no phonological phrase intervening between the adjective and its following noun, and so we see that [h]-epenthesis is not triggered at the end of the prosodic word, but at some larger prosodic constituent. Once again, we know that $[\mathrm{h}]$-epenthesis is not conditioned by utterance boundaries alone because it appears phrase-medially, for example, before the onset of the verb phrase with pre-verbal subjects (50)-(51), though not between direct objects and post-verbal subjects (52).

a. Le alah x-ok-ik.

The boy INFL-enter-SS

The boy entered.

b. *Le ala x-ok-ik.

The boy INFL-enter-SS

The boy entered.

(51) a. Are le b'ah X-ok-ik.

FOC the gopher INFL-enter-SS

It was the gopher that entered.

b. *Are le b'a x-ok-ik. FOC the gopher INFL-enter-SS

\footnotetext{
${ }^{15}$ This assumes that utterances cannot be recursively embedded. Ideally there would be a phonetic or phonological property linked to utterance boundaries that could be used to test for phrase-medial utterance boundaries. The problem is that I know of no such phonological process. Perhaps future work on boundary tones could provide a way to test for utterance boundaries, which I would predict do not track phrase-medial CP boundaries.
} 
It was the gopher that entered.

Xr-il- $\otimes$ le b'a le alah.

INFL-see the gopher the boy

The boy saw the gopher.

Since $[\mathrm{h}]$-epenthesis must operate above the level of the prosodic word, but below the utterance, it must be triggered by either the phonological phrase or the intonational phrase. The following contrast shows that it must be the smaller of the two domains (53).

a. Are le b'a*(h) xr-il- $\bigotimes$ le ala*(h).

FOC the gopher INFL-see the boy

It was the gopher that the boy saw.

b. Man are $\operatorname{ta}(* \mathbf{j}) \mathrm{xr}-\mathrm{il}-*(\mathbf{o})$.

NEG FOC IRR INFL-see-SS

It wasn't him who he saw.

Obligatory $[\mathrm{h}]$-epenthesis occurs in immediately preverbal position and at the end of the clause (53-a), but phrase-final morphs only appear at the end of the clause. There cannot be a CVC clitic allomorph in directly preverbal position (53-b). Since these two phenomena have slightly different distributions, with $[\mathrm{h}]$-epenthesis operating over a smaller domain, it must be the case that the phrase-final morphs are sensitive to the intonational phrase, while $[\mathrm{h}]$-epenthesis is conditioned at the end of phonological phrases, since these are the last two prosodic constituents available.

Finally, a crosslinguistic property of intonational phrasing is its variability, for example, through the use of comma intonation (Edmonds 1970; Nespor and Vogel 1986; Potts 2002; Selkirk 2005, among others). While intonational phrasing (as observed through the distribution of phrase-final alternations) seems to be more tightly constrained in K'ichee' than in English, there are cases where special prosodic circumstances yield status suffixes where they would not otherwise be found. For example, the naturally occuring example in (54) shows that vocative parentheticals trigger status suffixes, even though they do not form their own clause (Can Pixabaj 2004, K'ache'laaj, ln. 168). Example (55) shows a similar fact for the quotative particle kacha' (Can Pixabaj 2004, K'ache'laaj, ln. 163).

(54) Xin-peet-ik, taat.

INFL-come-SS, sir.

I came, sir.

K'ax k'ol-ik, kacha'.

bad exist-SS, REP

It was bad, they say.

What these two examples share is that the relevant items must be set off by comma intonation. It seems that this intonation pattern, commonly associated with intonational phrasing, triggers the appearance of phrase-final morphs, which is a general effect of $\mathrm{K}$ 'ichee' parentheticals.

I have noted another similar effect in the course of doing fieldwork. ${ }^{16}$ When having a sentence repeated word for word, sometimes status suffixes or phrase-final clitics will appear phrase-medially. This seems to be due to list intonation, where every word belongs to its own

\footnotetext{
${ }^{16}$ I would like to thank Judith Aissen, who noticed the same effect in the course of her work, for bringing this phenomenon to my attention.
} 
intonational unit. Both this phenomenon and the earlier discussion of parentheticals further argue for a prosodic account in terms of intonational phrases, which have a more variable distribution when affected by such discourse level phenomena.

The conclusions reached here are not just analytically consistent, but they make sense from a cross-linguistic perspective. First, AnderBois (2008) finds that [h]-epenthesis in Yukatek Maya also occurs at the end of the phonological phrase, and so this feature is conserved across the family. Also, it makes sense that if phrase-final morphs are sensitive to a phonological boundary, that boundary should be the intonational phrase. The reason is that there is a close correspondence between the distribution of the phrase-final morphs and CPs. Earlier work on intonational phrasing in other languages uses notions like the root phrase (Edmonds 1970) or assertoric independence (Selkirk 2005) to state the distribution of $\iota$ phrases, and while K'ichee' is not a perfect fit, CPs are just large enough to stand alone as independent assertions, which makes this analysis at least plausible. In conjunction with the distributional facts just considered, it is even stronger.

\subsubsection{The interface mapping}

I have argued that the K'ichee' phrase-final morphs are conditioned at the right edge of intonational phrase boundaries, but we have also seen that the distribution of intonational phrases is dependent on syntax because the appearance of the phrase-final morphs correlates with the distribution of CPs. The solution is to have constraints governing the mapping from syntax to prosody that will capture the connection between CPs and intonational phrases, while tying the distribution of the phrase-final morphs to intonational phrase-finality.

The generalization that the phrase-final morphs appear when they can be adjacent to the right edge of a $\mathrm{CP}$ is without exception. To capture this, the constraint AlignR(CP,IP) must be active in K'ichee' (56).

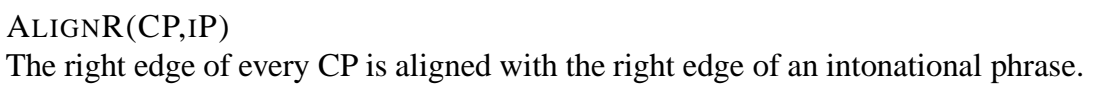

This constraint (56) ensures that when there are preverbal clausal adjuncts, there are two intonational phrases and therefore two positions to host phrase-final morphs. ${ }^{17}$

\section{NON-RECURSIVITY (Selkirk 1984)}

Let $\mathrm{C}_{i}$ and $\mathrm{C}_{j}$ be variables over levels of the prosodic hierachy. No $\mathrm{C}_{i}$ dominates $\mathrm{C}_{j}$ where $i=j$.

We kin-kos-ik kin-war-ik.

if INFL-tire-SS INFL-sleep-SS

If I get tired, I sleep.

\begin{tabular}{|l||c|}
\hline$\left((\text { we kinkos-ik })_{C P} \text { kinwarik }\right)_{C P}$ & ALIGNR(CP,IP $)$ \\
\hline \hline a. $(\text { we kinkos-ik })_{\iota-\text { phrase }}(\text { kinwarik })_{\iota-\text { phrase }}$ & \\
\hline b. $\left((\text { we kinkos-ik })_{\iota-\text { phrase }} \text { kinwarik }\right)_{\iota-\text { phrase }}$ & \\
\hline c. $(\text { we kinkos-ik kinwarik })_{\iota-\text { phrase }}$ & $*$ \\
\hline
\end{tabular}

\footnotetext{
${ }^{17}$ Although we assume NON-RECURSIVITY is active, we leave it out of the following examples until it is necessary in (65).
} 
The constraint in (56) is not the only necessary alignment constraint. When there are post-verbal embedded CPs, like complement clauses or headless WH-relatives, there are not enough boundaries if only ALIGNR(CP,IP) is active (61).

(60) Xinw-il-o chi xe'-el-ik.

INFL-see-SS that INFL-left-SS

I saw that they left.

\begin{tabular}{|l||l|}
\hline$\left(\text { xinwil-o }(\text { chi xe'el-ik })_{C P}\right)_{C P}$ & $\operatorname{ALIGNR}(\mathrm{CP}, \mathrm{IP})$ \\
\hline \hline a. $(\text { xinwil-o })_{\iota-\text { phrase }}(\text { chi xe'el-ik })_{\iota}$-phrase & \\
\hline b. $\left((\text { xinwil-o })_{\iota-\text { phrase }} \text { chi xe'el-ik }\right)_{\iota-\text { phrase }}$ & \\
\hline c. $(\text { xinwil-o chi xe'el-ik })_{\iota-\text { phrase }}$ & \\
\hline
\end{tabular}

The problem is that the right edge of the embedded and matrix CP coincide, so we cannot distinguish candidate (61a-b) from (61c), yet there are two phrase-final morphs and so we should expect the phrasing in (61a-b). ${ }^{18}$ One possible solution would be available if embedded clauses were to extrapose to $\mathrm{CP}$. This would provide a right $\mathrm{CP}$ boundary for the alignment constraint to target (62).

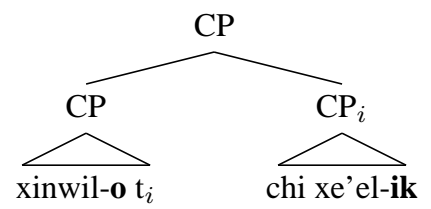

Complement clauses must extrapose over all post-verbal arguments and adjuncts, so an analysis like (62) is available for complement clauses. The problem is that it does not completely generalize. Headless WH-relatives condition phrase-final morphology (63-a), yet they cannot extrapose (63-b).

a. Xki-tij-o [jas xuyloq'-o] le ixoqib'. INFL-eat-SS what INFL-buy-SS the women The women ate what he bought.

b. *Xki-tij- $\otimes$ le ixoqib' [jas xu-loq'-o].

INFL-eat the women what INFL-buy-SS

The women ate what he bought.

Since not all embedded clauses obligatorily extrapose, extraposition will not always ensure that there is a right $\mathrm{CP}$ boundary between a matrix $\mathrm{V}^{\circ}$ and an embedded $\mathrm{CP}$. In order to do so, the alignment constraint ALIGnL(CP,IP) is necessary (64). Under an analysis using this constraint, the right intonational phrase edge (which conditions the appearance of the phrase-final suffixes), arises as a consequence of NON-RECURSIVITY (65).

(64) AlignL(CP,IP)

The left edge of every $\mathrm{CP}$ is aligned with the left edge of an intonational phrase.

\footnotetext{
${ }^{18}$ Even though we expect the recursive candidate in $(61 \mathrm{~b})$ to be ruled out, it still shows the insufficiency of ALIGNR(CP,IP) since there is no right $\mathrm{CP}$ at the matrix clause to force the appearance of a prosodic boundary, which we see from candidate $(61 \mathrm{c})$.
} 
(65)

\begin{tabular}{|c|c|c|c|}
\hline$\left(\right.$ xinwil-o $\left(\text { chi xe'el-ik) }{ }_{C P}\right)_{C P}$ & NON-REC & AlignR(CP,IP) & ALIGNL(CP,IP) \\
\hline a. $(\text { xinwil-o })_{\iota-\text { phrase }}(\text { chi xe'el-ik })_{\iota-\text { phrase }}$ & & 1 & i \\
\hline b. $\quad\left((\text { xinwil-o })_{\iota-\text { phrase }} \text { chi xe'el-ik }\right)_{\iota-\text { phrase }}$ & $*$ & $\begin{array}{l}1 \\
1\end{array}$ & $*$ \\
\hline c. (xinwil-o (chi xe'el-ik) $)_{\iota-p h r a s e}$ & $*$ & $\begin{array}{l}1 \\
1 \\
1\end{array}$ & \\
\hline d. (xinwil-o chi xe'el-ik) $\iota_{\iota-p h r a s e}$ & & $\begin{array}{l}1 \\
1\end{array}$ & $*$ \\
\hline
\end{tabular}

The alignment constraints in (56) and (64) generate the correct distribution of intonational phrase boundaries, except for the singular case where a relational noun takes a CP complement. We currently predict incorrectly that no phrase-final suffixes will appear at the VP juncture. The optimal candidate phrases rumal apart from its complement, causing it to intervene between the intonational phrase boundary and any phrase-final morphemes the verb could host (67).

(66) Xin-kos-ik rumal xin-chakun-ik.

INFL-tire-SS because INFL-work-SS

I am tired because I worked.

\begin{tabular}{|l||c:c|c|}
\hline$\left(\text { xinkos-ik rumal }(\text { xinchakun-ik })_{C P}\right)_{C P}$ & NON-REC & ALIGNR(CP,IP) & ALIGNL(CP,IP) \\
\hline \hline a. ${\text { (xinkos-ik rumal })_{i p}(\text { xinchakun-ik })_{i p}}$ & & & $*$ \\
\hline b. $\odot(\text { xinkos-ik })_{i p}(\text { rumal xinchakun-ik })_{i p}$ & & & $*$ \\
\hline c. $\quad(\text { xinkos-ik })_{i p}\left(\text { rumal }(\text { xinchakun-ik })_{i p}\right)_{i p}$ & $*$ & & \\
\hline
\end{tabular}

Notice that the unattested phrasing in the winning candidate separates a functional head and its complement by an intonational phrase boundary. It has been known for a long time that prosodic phrasing, especially intonational phrasing, is sensitive to functor-argument relations. There have been a variety of proposals to capture this observation, for example, the SENSE UNIT CONDITION. See Steedman (2000) for a similar idea in categorial grammar and Watson and Gibson $(2004,2005)$ for a processing account. In OT terms, the intuition is that it is marked to phrase heads, especially functional heads, separately from their arguments. In the spirit of Werle (2004), I propose the constraint in (68) to capture this intuition. ${ }^{19}$

COMPLEMENT- $\phi$

A functional head is parsed into the same phonological phrase as its syntactic complement.

Ranking (68) above alignment generates the desired output.

\begin{tabular}{|c|c|c|c|c|}
\hline$\left(\text { xinkos-ik rumal (xinchakun-ik) }{ }_{C P}\right)_{C P}$ & NON-REC & ALIGNR & $\mathrm{COMP}_{\phi}$ & ALIGNL \\
\hline a. $\quad(\text { xinkos-ik rumal })_{i p}(\text { xinchakun-ik })_{i p}$ & & & $*$ & \\
\hline b. $(\text { xinkos-ik })_{i p}(\text { rumal xinchakun-ik })_{i p}$ & & & & $*$ \\
\hline c. $\left.\quad(\text { xinkos-ik })_{i p}(\text { rumal (xinchakun-ik })_{i p}\right)_{i p}$ & $*$ & & * & \\
\hline
\end{tabular}

\footnotetext{
${ }^{19}$ Werle (2004) uses COMPLEMENT- $\omega$ to account for various patterns of functional head cliticization in Bosnian/Serbian.
} 
The winning candidate takes a violation of ALIGNL(CP,IP) in order to avoid a violation of the higher ranked $\operatorname{COMP}_{\phi}$. There is independent evidence that the constraint in (68) is high ranking in K'ichee'. The reason is that functional heads tend to prosodically incorporate into their complements. For instance, vowel final functional heads lose their final vowels when their complements are vowel initial (Larsen 1988; López Ixcoy 1997).

(70) Determiners
a. le ixoq $\rightarrow$ lixoq
the woman
b. ri alah $\rightarrow$ ralah
the boy

Prepositions

a. chi ab'iix $\rightarrow$ chab'iix to/at the cornfield

b. pa awochooch $\rightarrow$ pawochooch to/at your house

A similar, though slightly different effect can be seen with the negative operator man. When its argument is consonant initial, the final nasal is lost as in (72). This is not true when negation takes a vowel initial argument, for example, the focus particle aree in (73-a) (Larsen 1988; López Ixcoy 1997). ${ }^{20}$
a. man pawib' taj $\rightarrow$ ma pawib' taj
not above you
b. man xakam taj $\rightarrow$ ma xakam taj
you didn't carry it

Man aree ta ri alah xkosik $\rightarrow$

a. man aree ta ralah $\mathrm{x}$-kos-ik.

NEG FOC IRR DET.boy INFL-tired-SS

It wasn't the boy who got tired.

The constraint in (68) allows us to understand both of these effects as arising from prosodic incorporation of functional heads into their complements.

Although the relational nouns do not participate in these particular phenomena, there is independent evidence that umaal must be phrased with its complement. There is a phonological process in K'ichee' that shortens certain long vowels unless they are phrase-final. ${ }^{21}$ The relational noun denoting reason contains one of these long vowels (74). Crucially, the long vowel behaves the same with respect to both nominal and clausal complements (76).

a. Xin-kos- $\otimes$ rumaal.

INFL-tired because

\footnotetext{
${ }^{20}$ In light of the ma/man alternation, one might worry that the alternation between ta/taj might not be completely about phrasal location, but a combination of location in the phrase and following material. Note, though, that we see $t a$ phrase-medially before words that start with both consonants and vowels, for instance, example (73-a) versus (9).

${ }^{21}$ Long vowels have two sources in K'ichee' (Campbell 1977). The first are the long vowels present in Proto-K'ichean, which are preserved in those dialects of K'ichee' that have long vowels. The second set of long vowels appear in closed syllables that historically have a CVhC shape source. K'ichee' lost [h] syllableinternally, which was replaced with vowel length.
} 
I am tired because of it.

b. *Xin-kos- $\otimes$ rumal.

INFL-tired because

I am tired because of it.

a. We kin-kos- $\otimes$ rumaal, kin-war-ik.

if INFL-tired because INFL-sleep-SS

If I get tired because of it, I sleep.

b. *We kin-kos- $\otimes$ rumal, kin-war-ik

if INFL-tired because INFL-sleep-SS

If I get tired because of it, I sleep.

a. rumal/*rumaal xin-chakun-ik

because INFL-work-SS

because I worked

b. rumal/*rumaal nu-chaak

because of my-work

because of my work

The lack of contrast between (76-a) and (76-b) compared to (74) and (75) indicates that there is no intonational phrase boundary between rumaal and its clausal complement, which means it must be phrased within its complement.

The constraint ranking in (77) correctly maps syntactic structure to high level prosodic structure in K'ichee'.

$$
\text { COMPLEMENT }_{\omega}>>\text { AlignL(CP,IP),NON-RECURSIVITY,AlignR(CP,IP) }
$$

$\mathrm{CP}$ boundaries in K'ichee' correspond to intonational phrase boundaries, except where this would lead to functional heads being phrased separately from their arguments. Once CPs define intonational phrase boundaries, the rest of the clause is completely parsed into prosodic structure in a way that avoids recursivity. The result of the analysis in (77) is that the syntax will be parsed so that the phrase-final morphs appear if and only if they are rightmost in the intonational phrase. In the next section I show that this distribution is not accidental. Independently, K'ichee' requires a stress peak to be aligned rightmost in the intonational phrase domains generated by (77). This will allow us to understand the phrase-final morphological alterations as optimization for stress placement, and will further support the distributional patterns discussed in this section.

\section{An output optimization account of phrase-final morphological alternations}

The previous section showed that phrase-final morphs in K'ichee' appear at the end of intonational phrases and gave a syntax-prosody mapping algorithm to derive the distribution of intonational phrases. But we still do not understand why these boundaries should matter, and why we get the distribution of morphemes that we actually see. For example, why is the attested pattern for the distribution of the status suffixes (78), and not (79), where status suffixes are deleted at $\iota$-phrase boundaries? We can pose the same question for the distribution of CVC clitic allomorphs (80)-(81). 
(78) Status suffixes

a. Xe-kos- $\otimes$ le tz'i'. $)_{\iota-p h r a s e}$

INFL-tire the dogs

The dogs got tired.

b. Le tz'i' xe-kos-ik. ) ( $\iota$-phrase

The dogs INFL-tire-SS

The dogs got tired.

a. *Xe-kos-ik le tz'i'. $)_{\iota-p h r a s e}$

INFL-tire the dogs

The dogs got tired.

b. *Le tz'i' xe-kos- $\otimes . \quad)_{\iota-p h r a s e}$

The dogs INFL-tire-SS

The dogs got tired.

(80)

Clitic alternations

a. Man xki-tij- $\otimes$ ta le tz'i'. $)_{\iota-p h r a s e}$

NEG INFL-eat IRR the dogs

The dogs didn't eat it.

b. Le tz'i' man xki-tij- $\otimes$ taj. $)_{\iota-\text { phrase }}$

The dogs NEG INFL-eat IRR

The dogs didn't eat it.

a. *Man xki-tij- $\bigotimes$ taj le tz'i'. $)_{\iota-p h r a s e}$

NEG INFL-eat IRR the dogs

The dogs didn't eat it.

b. *Le tz'i' man xki-tij- $\otimes$ ta. $)_{\iota-p h r a s e}$

The dogs NEG INFL-eat IRR

The dogs didn't eat it.

We can answer these questions when we treat phrase-final morphological alternations as optimizing phonological outputs. Although there is not a uniform explanation for the two classes of phrase-final morphology, in each case we must make use of the independent fact that K'ichee' aligns stress with the rightmost syllable in the intonational phrase (though it does not otherwise require stress to be rightmost in the prosodic word). Since we can tie allomorphy selection to independent facts about stress placement, we are able to analyse both clitic alternations and status suffix placement in terms of output optimization. This is an important result, especially for the status suffix placement, because at first pass the distribution of status suffixes seems most amenable to an analysis that makes use of prosodic subcategorization frames. The crucial insight is that status suffixes are lexically specified as heading a section of prosodic structure, analagous to other cases of affix-controlled stress (Alderete 1999). The fact that K'ichee' phrase-final allomorph selection is optimizing for stress placement is interesting because it allows us to assimilate these phenomena to the much more common cases where suppletive allmorphy is triggered by metrical structure at the word or foot level (Paster 2006). The reason why morphological alternations in K'ichee' 
are triggered at such a large boundary is that intonational phrases in K'ichee' affect stress placement.

\subsection{The K'ichee' stress system}

Since I will argue that K'ichee' phrase-final morphological alternations are phonologically optimizing for stress placement, an understanding of the K'ichee' stress system is a prerequisite to the analysis. In what follows, I will assume that heavy syllables are bimoraic and light syllables are monomoraic. I also assume that long vowels are bimoraic and that coda consonants bear a mora in K'ichee'. The generalization in (82) captures the distribution of primary stress in K'ichee'.

\section{K'ICHEE' STRESS GENERALIZATION}

Stress falls on the final syllable of a prosodic word, unless that syllable is light non-root material, in which case it falls on the final root syllable.

The first part of the generalization is that stress is attracted to the right edge of the prosodic word. Examples (83)-(84) show that stress falls on the rightmost syllable if it is a root syllable or a heavy affix.
a. $\quad$ in $-\sqrt{b^{\prime} e}$
INFL-go
I went.
b. xinb'é
a. $\sqrt{w a r}$-eem
sleep-INF
sleep
b. waréem

Although primary stress is preferred word-finally, even if it must fall on a light root syllable, the situation is different with clitics and affixes. Light clitics and affixes cannot bear primary word stress. Instead, it falls on the root. Consider the attributive adjective suffix $-a$, which never bears stress.
$\sqrt{s a q}-\mathrm{a}$
white-ADJ
white
b. sáqa ...

Similarly, the status suffix -oq alternates with $-a$ in phrase-medial position. When $-a$ appears, it is never stressed. The stress falls on the final root syllable.
a. kat- $\sqrt{e l}$-a ...
INFL-leave-IMP
Leave!
b. katéla ...

The facts that hold for light affixes also hold for light clitics. Even if we have a string of clitics, if they are light, stress falls on the root (87). 


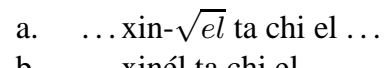

b. ... xinél ta chi el ...

The data can be analyzed straightforwardly in OT. First, we know that a constraint like $\operatorname{ALIGN}_{\omega}($ peak,$R)$ is operative in K'ichee' (Prince and Smolensky 1993).

\section{$\operatorname{ALIGN}_{\omega}($ peak,$R)$}

A peak of prominence lies at the right edge of the prosodic word.

The reason is that K'ichee' prefers stress on the rightmost syllable. Notice that we cannot account for this with foot form constraints like IAMB or TROCHEE. K'ichee' stress does not permit a trochaic analysis because there are forms like (90), which should be barred from trochaic languages.
a. mexá
table
b. kaltóh
soup

The problem is that in balanced feet like those in (90), we should have stress on the first syllable, but we don't. Thus, K'ichee' cannot be trochaic. We also know that K'ichee' does not foot iambs for stress placement because of forms like (91).
a. xinb'é ...
I went.
b. katpé ...
You came.

Although there are not many forms of this type, they pose a problem for iambic treatments of K'ichee' stress because they are of uneven weight. Typologically, we know that iambic languages are weight sensitive (Hayes 1995). In iambic languages the final syllable of an H.L sequence is either not footed or made heavy, but neither happens in K'ichee'. Since we cannot account for stress placement with foot form constraints, it is better to analyze syllable final stress in K'ichee' with a constraint like $\operatorname{ALIGN}_{\omega}($ peak, $R$ ).

That being said, we saw that primary stress does not always fall on the final syllable. There is a preference for stress to fall on the root when $\operatorname{ALIGN}_{\omega}($ peak, $R)$ would force it to fall on light non-root material. Crucially, we cannot just use a constraint that punishes stress on affixes, like STRESS to RoOT, since we can stress heavy affixes. At the same time we cannot use a constraint that punishes stress on light syllables, like STRESS TO WEIGHT, since light root syllables can be stressed. Thus we need both of these constraints, and they must be ranked over $\operatorname{ALIGN}_{\omega}($ peak, $R)(94)$.

$$
\begin{aligned}
& \text { STRESS TO ROOT (STR) }{ }^{22} \\
& \text { Primary stress coincides with the root. }
\end{aligned}
$$

\footnotetext{
${ }^{22}$ This constraint is in the spirit of COINCIDE constraints (Zoll 2004), which require heavy syllables, stress, etc. to occur in strong root positions.
} 
StRESS TO Weight (STW)

Stressed syllables are heavy.

Stress to WeIght, Stress to Root $>>\operatorname{ALIGN}_{\omega}(p e a k, R)$

Although we have the correct set of constraints, the ranking in (94) does not work because no matter how we order STR and STW with respect to each other, we predict ungrammatical stress patterns. If STR is ranked above STW we correctly predict that rightmost light root material gets primary stress (96), but we incorrectly predict that heavy affixes should not be able to carry primary stress (98).

a. $\quad \operatorname{xin}-\sqrt{b^{\prime} e} \ldots$

INFL-go ...

I went.

b. xinb'é

\begin{tabular}{|c|c|c|c|}
\hline $\operatorname{xin}-\sqrt{b^{\prime} e}$ & STR & STW & $\operatorname{ALIGN}_{\omega}$ \\
\hline a. xinb'é & & $*$ & \\
\hline b. xínb'e & * & & * \\
\hline
\end{tabular}

a. $\sqrt{w a r}$-eem

sleep-INF

sleep

b. waréem

\begin{tabular}{|c|c|c|c|}
\hline$\sqrt{w a r}$-eem & STR & STW & $\operatorname{ALIGN}_{\omega}$ \\
\hline a. :) waréem & $*$ & & \\
\hline b. 吗 wáreem & & * & * \\
\hline
\end{tabular}

If we switch the order of STR and STW, we recreate the problem in the other direction. We can no longer capture the fact that light root material gets primary stress.

To solve the ranking paradox, we must either posit some higher ranking constraint to mitigate the pernicious effects of one of the constraints in the paradoxical relationship, or we must use constraint conjunction. I will take the latter option. The reason for not breaking the ranking paradox with a higher ranked constraint is that there is no such constraint. When STR ranks over STW, we need a constraint that would punish heavy root-final material, which is precisely the most harmonic place for stress placement. When STW ranks over STR we need a constraint to punish stressed non-final syllables (specifically those that satisfy STW), but this is just $\operatorname{ALIGN}_{\omega}($ peak, $R$ ), which we already know must be ranked below both STR and STW.

Instead, I propose to introduce conjoined constraints, which assign violations only if all constituent constraints are violated. If we conjoin STR and STW, we get a constraint that will be evaluated locally, assigning violations to only those non-root stressed syllables that are light. Light stressed root syllables and heavy stressed non-root material will pass through this constraint, which is exactly the pattern that K'ichee' exhibits (99).

$$
\mathrm{STR} \wedge \mathrm{STW}>>\operatorname{ALIGN}_{\omega}(\text { peak, } R)
$$
a. $x \sin \sqrt{b^{\prime} e} \ldots$
b. xinb'é ... 
$(101)$

\begin{tabular}{|r||c|c|c|c|}
\hline \multicolumn{1}{|r|}{ xin- $\sqrt{b^{\prime} e}$} & STR $\wedge$ STW & ALIGN $\omega$ & STR & STW \\
\hline \hline a. xinb'é & & & & $*$ \\
\hline b. $\quad$ xínb'e & & $*$ & $*$ & \\
\hline
\end{tabular}

a. $\sqrt{w a r}$-eem

b. waréem

(103)

\begin{tabular}{|l||c|c|c:c|}
\hline \multicolumn{1}{|r|}{$\sqrt{w a r}-\mathrm{eem}$} & $\mathrm{STR} \wedge \mathrm{STW}$ & ALIGN $_{\omega}$ & $\mathrm{STR}$ & $\mathrm{STW}$ \\
\hline \hline a. waréem & & & $*$ & \\
\hline b. $\quad$ wáreem & & $*$ & & $*$ \\
\hline
\end{tabular}

(104) a. kat- $\sqrt{e l}-\mathrm{a} \ldots$

b. katéla ...

(105)

\begin{tabular}{|c|c|c|c|c|}
\hline kat- $\sqrt{e l}-\mathrm{a}$ & $\mathrm{STR} \wedge \mathrm{STW}$ & $\operatorname{ALIGN}_{\omega}$ & STR & STW \\
\hline a. katelá & * & & * & * \\
\hline b. katéla & & $*$ & & * \\
\hline
\end{tabular}

The ranking in (99) captures the distribution of primary stress in K'ichee', including the tough examples we have just seen. Although we have to use conjoined constraints, it is a natural implementation of constraint conjunction. We know that there are languages that avoid stressing light syllables (Hayes 1995; Kager 1999), and at the same time, there are languages that avoid stress in weak, non-root positions (Zoll 2004). The conjoined constraint captures the intuition that stressing light syllables in weak positions would be especially bad. One might wonder if we could capture the same intuition using positional markedness constraints, for example, by relativizing STW to weak (non-root) positions.

$\mathrm{STW}_{\text {weak }}$

Stressed weak syllables are heavy.

The constraint in (106) does the same work as the conjoined constraint used above. Since there are no operational differences, the decision between the two is a conceptual one and depends on whether we want to add (106) to our typology of positional markedness constraints. I do not take this route because it is conceptually unappealing to have a positional markedness constraint preferring heavy syllables in weak position when heavy syllables avoid weak positions crosslinguistically (Zoll 2004), but I leave the final decision about the best analysis of K'ichee' stress for future work.

We now have an analysis of primary stress that completely accounts for its distribution at the level of the phonological word. What we will see is that larger level prosodic constituents impinge on the placement of word stress. Intonational phrases require the primary stress of the rightmost prosodic word to be aligned with its right boundary, even if it forces stress onto light non-root syllables. Therefore, while we do not have to align primary stress rightmost within a prosodic word, we must align stress with the right edge of an $\iota$-phrase. It is by this process that we get CVC clitics at the ends of $\iota$-phrases, since CVC clitics are better hosts for stress than their $\mathrm{CV}$ counterparts. 
Remember that K'ichee' has a set of clitics that alternate between CV and CVC forms at the ends of intonational phrases. Example (107) gives some examples of these clitics and their translations.
a. ta/taj
irrealis
b. k'u/k'ut
polarity question
c. chi/chik
again

While the two forms of these clitics are quite similar, there is evidence that they are not allomorphic variants of each other, but are actually in a suppletive relationship. For instance, we cannot derive the $\mathrm{CVC}$ form from an underlying $\mathrm{CV}$ form because the final consonants (consider $[\mathrm{k}, \mathrm{t}, \mathrm{j}]$ ) share no unifying features. Moreover, the default consonant for epenthesis is a glottal stop, which is used to prevent hiatus. ${ }^{23}$

While we cannot derive CVC clitics from their CV forms, we also cannot move in the other direction, deriving the smaller forms from the larger through phonological deletion. The problem is that there is no general coda deletion process to appeal to. In fact, K'ichee' privileges codas both morphologically and phonologically. The canonical root shape in the language has a final consonant, and we have already seen coda epenthesis in the form of final laryngeal strengthening. An analysis in terms of coda deletion would have to pick out these specific morphemes, which is a difficult task since there are other functional morphemes that commonly sit in the same post-verbal clitic field and which do not have to be CV phrasemedially.

The conclusion is that deriving the $\mathrm{CV}$ forms of the phrase-final clitics from their CVC forms would require lexically indexed constraints that specifically target these morphemes (McCarthy and Prince 1993; Pater 2000). While lexically indexed constraints are a possibility that I leave open, I will not take this path. Instead, I will treat the two forms as suppletive allomorphs. Even though suppletion might seem to require just as much lexical stipulation, it yields important analytic insights. Once we have the two forms in the lexicon, we will see that the CVC form appears when it can optimize stress placement, while the CV form appears elsewhere as a case of the emergence of the unmarked (TETU) (McCarthy and Prince 1986/1996).

\footnotetext{
${ }^{23}$ For example, when the third person absolutive plural morpheme $e$ is prefixed to a vowel initial root, a glottal stop is inserted. If the clitic alternations were a case of epenthesis, we would expect this unmarked consonant to appear.
}

(i) $\quad$ a. $\mathrm{X}$-e-ul-ik.

INFL-A3p-arrive-SS

They arrived

b. X-e-b'e-ik.

INFL-A3p-go-SS

They went 


\subsubsection{Prosodically conditioned allomorphy in OT}

OT approaches to suppletive allomorphy model suppletion as phonological competition between the members of the set of allomorphs (Mascaró 2007; Mester 1994). The allomorphs are in competition in the input, and the more harmonic morpheme is inserted depending on the phonological environment. The crucial environment for the phrase-final clitic alternations is the right edge of the intonational phrase. It is only here that we see the CVC allomorph. The reason is that K'ichee' has a high ranking constraint aligning a peak of prominence with the right edge of the intonational phrase, which forces the insertion of the CVC allomorph because it is better able to bear this prominence. Elsewhere, the clitic appears in its CV form, which we can attribute to a TETU effect of NO-CODA.

In the discussion of K'ichee' stress, we saw that while stress usually appears on the final syllable of the prosodic word, this is only due to the fact that most words end in a consonant. If the last syllable is light and affixal, stress falls on the final root syllable. The situation is different at the end of the intonational phrase. It is a strong generalization that we always have a stress peak aligned with the right edge of the intonational phrase. For instance, some clitics have only a CV form, like the aspect clitic na. Phrase-medially, such clitics are not stressed, but when they abut the intonational phrase, they bear stress (108).

a. Kin-tíj- $\bigotimes$ na le ak'.

INFL-eat ASP the chicken

I am going to eat the chicken.

b. Kin-tij- $\bigotimes$ ná.

INFL-eat ASP

I am going to eat it.

This is evidence that while our conjoined constraint STR $\wedge$ STW ranks over the constraint aligning a stress peak to the right edge of the prosodic word, there is a higher ranking alignment constraint forcing stress to be rightmost in the intonational phrase (109).

$\mathrm{ALIGN}_{\iota}(\mathrm{PEAK}, \mathrm{R})$

A peak of prominence lies at the right edge of the intonational phrase.

\begin{tabular}{|r||c|c|c|}
\hline kintij na $)_{\iota-\text { phrase }}$ & ALIGN $_{\iota}$ & STR $\wedge \mathrm{STW}_{1}$ & ALIGN $_{\omega}$ \\
\hline \hline a. ${ }^{\prime}$ kintij ná $)_{\iota-\text { phrase }}$ & & $*$ & \\
\hline b. kintij na $)_{\iota-\text { phrase }}$ & $*$ & & $*$ \\
\hline
\end{tabular}

Now consider what happens when one of the clitics that participates in phrase-final alternations appears at the end of the intonational phrase under the ranking in (110). Since both the $\mathrm{CV}$ and $\mathrm{CVC}$ allomorphs are available in the input to be inserted without a faithfulness violation, inserting the $\mathrm{CVC}$ form is more harmonic than inserting the $\mathrm{CV}$ allomorph, which cannot bear the intonational phrase peak without violating STR $\wedge$ STW (112).

\footnotetext{
Kin-b'e- $\bigotimes$ taj.

INFL-go IRR

I would go.
} 
(112)

\begin{tabular}{|c|c|c|c|}
\hline xinb'e $\{$ ta $/$ taj $\})_{\iota-\text { phrase }}$ & $\mathrm{ALIGN}_{\iota}$ & $\mathrm{STR} \wedge \mathrm{STW}$ & $\operatorname{ALIGN}_{\omega}$ \\
\hline a. xinb'é ta $)_{\iota-\text { phrase }}$ & $*$ & & $*$ \\
\hline b. xinb'e tá $)_{\iota-\text { phrase }}$ & & $*$ & \\
\hline c. xinb'e táj $)_{\iota-\text { phrase }}$ & & & \\
\hline
\end{tabular}

While we now correctly predict that CVC clitic allomorphs will surface at the ends of intonational phrases, we do not capture the second half of the generalization, namely, that the CV allomorph appears elsewhere.

\begin{tabular}{|l||c|c|c|}
\hline xinb'e $\{$ ta $/$ taj $\left.\})_{\omega} \ldots \sigma\right)_{\iota-\text { phrase }}$ & ALIGN $_{\iota}$ & STR $\wedge \operatorname{STW} \operatorname{ALIGN}_{\omega}$ \\
\hline \hline a. $\odot$ xinb'é ta $\left.)_{\omega} \ldots \sigma^{\prime}\right)_{\iota-\text { phrase }}$ & & & $*$ \\
\hline b. $\quad$ xinb'e tá $\left.)_{\omega} \ldots \sigma^{\prime}\right)_{\iota-\text { phrase }}$ & & $*$ & \\
\hline c. ${ }^{\prime}$ xinb'e táj $\left.)_{\omega} \ldots \sigma^{\prime}\right)_{\iota-\text { phrase }}$ & & & \\
\hline
\end{tabular}

The tableau shows that we should also pick the CVC clitic allomorphs phrase-medially in order to align primary stress rightmost in the prosodic word. The approach to suppletive allomorphy taken here allows us to understand why this does not happen in terms of TETU. The reason is that since both allomorphs are in competition in the input, either can be used without a faithfulness violation. The result is that we choose the more unmarked form with respect to some markedness constraint that is otherwise masked by faithfulness. In this case, the crucial markedness constraint is NoCODA. While codas abound in K'ichee', which we can attribute to MAX outranking NoCODA, choosing the CV allomorph from a set of allomorphs incurs no violation of MAX. This means that in cases of suppletive allomorphy we should see the emergent effects of NOCODA, which is precisely what happens when CV clitic allomorphs appear phrase-medially. ${ }^{24}$ When the $\iota$-phrase peak alignment constraint is satisfied by some other syllable, competition between clitic allomorphs is settled by NoCODA $(116){ }^{25}$

\begin{tabular}{|c|c|c|c|c|}
\hline xinb'e $\{$ ta/taj $\left.\})_{\omega} \ldots \sigma\right)_{\iota-\text { phrase }}$ & $\begin{array}{l:l}\operatorname{MAX} & \operatorname{ALIGN}_{i} \\
\end{array}$ & $\mathrm{STR} \wedge \mathrm{STW}$ & NoCoda & $\operatorname{ALIGN}_{\omega}$ \\
\hline a. xinb'é ta $\left.)_{\omega} \ldots \sigma^{\prime}\right)_{\iota-\text { phrase }}$ & i & & $*$ & $*$ \\
\hline b. $\quad$ xinb'e tá $\left.)_{\omega} \ldots \sigma^{\prime}\right)_{\iota-\text { phrase }}$ & $\begin{array}{l}1 \\
1\end{array}$ & $*$ & $*$ & \\
\hline c. xinb'e táj $\left.)_{\omega} \ldots \sigma^{\prime}\right)_{\iota-p h r a s e}$ & 1 & & $* *$ & \\
\hline
\end{tabular}

We now have a full understanding of phrase-final clitic alternations in K'ichee'. Although they must be treated as suppletion, once the two allomorphs are in the lexicon, we can derive their distribution through the constraints independently needed for the K'ichee' stress system and universal markedness. The CVC clitic allomorph appears at the ends of intonational phrases because K'ichee' aligns a stress peak at the right edge of the intonational phrase and

\footnotetext{
${ }^{24}$ I am very greatful to Junko Itô for pointing this out.

${ }^{25}$ Although we do not build an analysis of [h]-epenthesis, a reviewer notes that the constraint requiring the epenthesis of laryngeal features would have to outrank No-CODA. We do not have to worry about phrasemedial clitics undergoing $[\mathrm{h}]$-epenthesis because this process is a word minimality effect that only targets lexical, not functional, morphemes.
} 
the CVC allomorph is better able to host this stress peak. Elsewhere, the CV allomorph appears due to TETU effects of NoCODA. Phrase-final clitic allomorphy in K'ichee' presents a classic case of prosodically conditioned suppletive allomorphy. But it is especially interesting because it is sensitive to higher levels in the prosodic hierarchy, whereas most of the cases of prosodically conditioned suppletive allomorphy in the literature are conditioned by prosodic structure at the word level (Paster 2006). The connection between phrase-final clitic alternations and previously studied cases of prosodically conditioned suppletive allomorphy is that intonational phrases in K'ichee' affect aspects of word level prosodic structure by forcing a stress peak to be aligned rightmost in its domain. ${ }^{26}$

\subsection{Status suffixes and output optimization}

The K'ichee' status suffixes have the same distribution as CVC clitic allomorphs, but the phonological process governing their distribution must be different. The reason is that we cannot attribute the appearance of status suffixes to the optimization of stress placement in the $\iota$-phrase domain. Since almost all verbs in K'ichee' end in a consonant, we do not need the status suffixes in order to align the peak prominence of the $\iota$-phrase rightmost. For example, there is no improvement with respect to prominence alignment in (115-a) over (115-b).
a. *Xin-kós- $\bigotimes$.
INFL-tire
I am tired.
b. Xin-kos-ík.
INFL-tire-SS
I am tired.

The contrast in (115) shows that the analysis we gave for the clitic alternations cannot be extended to account for the distribution of phrase-final status suffixes. The insertion of status affixes at intonational phrase boundaries is at least non-optimizing with respect to prominence alignment. And as (116) shows, in some cases it is anti-optimizing.
a. Xin-tij-ó.
INFL-eat-SS
I ate it.
b. Xin-tíj- $\otimes$ le sub'.
INFL-eat the tamalito
I ate the tamalito.

We saw that K'ichee' avoids making light affixes the heads of prosodic words, yet the $o$ status suffix appears if and only if it receives stress. The problem is that the status suffix need not appear, as we see in (116-b). But then we would also expect the suffix not to appear in (116-a) because this would be more harmonic with respect to stress placement.

\footnotetext{
${ }^{26} \mathrm{~A}$ reviewer notes that the pausal forms of Tiberian Hebrew present another case where intonational phrase prominence affects word level prosody (Dresher 1994, among others), though in this case stress is forced aways from its normal position at the right edge of the word.
} 
OT approaches to suppletive allomorphy have trouble with patently non-optimizing prosodically conditioned suppletive allomorphy. The reason is that allomorphy should be driven by independently motivated prosodic constraints outranking morphological constraints, or it should be attributable to the emergence of the unmarked. Although at first pass the status suffixes appear to be a good candidate for a treatment with prosodic subcategorization frames (Inkelas 1990; Paster 2006), I will argue that we can better understand their distribution in terms of output optimization, using a natural extension of work by Alderete (1999) on affix controlled stress.

Alderete (1999) presents a series of languages where individual affixes are lexically specified for stress, and actual stress placement is determined by the properties of the root and whether or not the affix is inherently stressed. But what does it mean for an affix to be lexically specified for stress? Alderete's conception is that stress is an autosegmental unit, specifically, a mark in a metrical grid (Halle and Idsardi 1994; Liberman and Prince 1977), and that morphemes can be associated with grid marks in the input. ${ }^{27}$ Ignoring different levels of prominence like secondary stress a morpheme that is lexically specified for primary word stress would be associated with a grid mark in the input. With grid marks in the input, we can now have our full complement of faithfulness constraints to input prominences. Alderete only considers cases of accent at the level of the prosodic word, but there is nothing in his theory prohibiting morphemes from lexically requiring prominence at higher levels of prosodic structure. If the status suffixes fit into this wider class, we can explain the distribution in terms of output optimization, while avoiding some of the problems with alignment or subcategorization approaches.

I will assume that prominence at different levels of the prosodic hierarchy corresponds to different levels of prominence in the metrical grid. Word stress corresponds to prominence at level one of the metrical grid, while the head syllable of the phonological phrase would have two marks in the metrical grid, and intonational phrase prominence would correspond to three grid marks (118).

Are le bah x-ul-ik.

FOG the gopher INFL-arrive-SS

It was the gopher that arrived.

$\begin{array}{cccc}\iota & & & \text { X } \\ \phi & & \text { X } & \text { X } \\ \omega & \text { X } & \text { X } & \text { X } \\ & \left(\left((\text { Are })_{\omega}\right.\right. & (\text { le bah }) \omega)_{\phi} & \left.\left((\text { xul-ik })_{\omega}\right)_{\phi}\right)_{\iota}\end{array}$

The proposal for the phrase-final status suffixes is that they are specified for intonational phrase prominence in the input, that is, they have grid marks up to level three (119). There is evidence in K'ichee' that the number of marks a syllable carries reflects phonetic realization. The final stress in the intonational phrase is strongest and carries a rising boundary tone. ${ }^{28}$ Every time the status suffixes appear they carry this strongest stress. I will use the notation in (120) as a shorthand for (119), and similarly for prominence at the prosodic word $(\omega)$ and the phonological phrase $(\phi)$.

\footnotetext{
${ }^{27}$ Crucially, this presupposes that prominence grid marks are independent phonological objects. See Hyde (2007) for independent arguments that this is the case.

${ }^{28} \mathrm{~A}$ reviewer wonders whether the phrase-final status suffixes, and not intonational phrase prominence, could bear the boundary tone in the input. This is possibile as long as the tone can force stress onto the final syllable of the intonational phrase. Since $\iota \mathrm{P}$ prominence and $\iota \mathrm{P}$ boundary tones have the same distribution, it is not clear whether we can empirically distinguish associating a morpheme with an $\iota \mathrm{P}$ prominence from associating it with an $\iota \mathrm{P}$ boundary tone.
} 
(119)

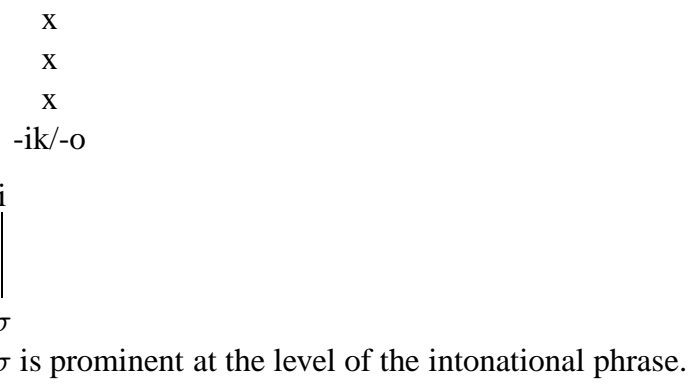

(120)

$\sigma$ is prominent at the level of the intonational phrase.

Since we independently require a peak of prominence to be aligned rightmost in the intonational phrase, the status suffixes will be able to appear faithfully when the verb is rightmost in the intonational phrase (122). We can see from the violation that the winning candidate receives from STR $\wedge$ STW that faithfully realizing status suffixes can run counter to the normal stress patterns in the language, where light affixal material is unstressed.
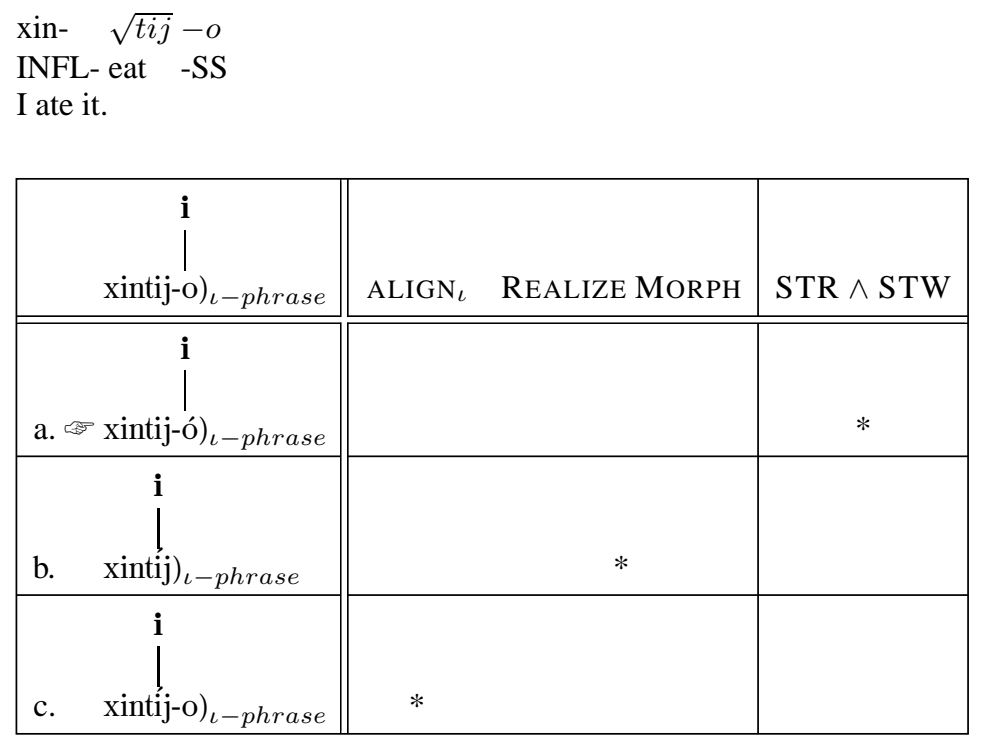

Phrase-medially, high ranking faithfulness constraints will force the deletion of the status suffixes (123).

\section{IDENTPROM}

If morpheme $M$ has prominence $P$ in input, $M$ has prominence $P$ in the output.

The constraint in (123) will require the status suffix to appear faithfully, that is, prominent at the intonational phrase level. If this is impossible, it is better to violate REALIZE MORPHEME (124) than to realize it unfaithfully or to violate other prosodic constraints. ${ }^{29}$

\footnotetext{
${ }^{29}$ For those who do no like the constraint REALIZE MORPHEME, and alternative analysis can be built using zero-allomorphs. If the status suffixes alternate with the zero-morph, then we can use the constraint PRIORTY (Mascaró 2007) to favor the visible allomorph unless this would cause violations of the higher ranking alignment constraints, in which case the zero-morph would be inserted. The problem with this analysis is we must stipulate that each phrase-final status suffix alternates with the zero-morph, and in the end, this lexical stipulation does not even reduce the number of constraints needed for the analysis.
} 
REALIZE MORPHEME

Every morpheme in the input has a phonological exponent in the output.

\begin{tabular}{|c|c|c|c|c|}
\hline$\left.\right|_{\left.\mathrm{xintij}-\mathrm{o})_{\omega} \ldots \sigma\right)_{\iota-\text { phrase }}} ^{\mathbf{i}}$ & IDENTPROM & $\begin{array}{l}\text { ALIGN } \\
\vdots \\
1\end{array}$ & RMORPH & $\mathrm{STR} \wedge \mathrm{STW}$ \\
\hline 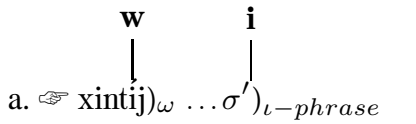 & & & $*$ & \\
\hline 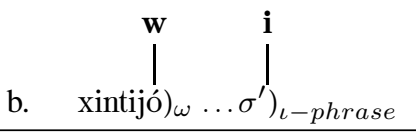 & $*$ & $\begin{array}{l}\text { i } \\
\text { a }\end{array}$ & & $*$ \\
\hline$\left.\right|_{\left.\text {c. } \quad \text { xintij-ó })_{\omega} \ldots \sigma^{\prime}\right)_{\iota-\text { phrase }}} ^{\mathbf{i}}$ & & $\begin{array}{l}1 \\
\vdots \\
1\end{array}$ & & $*$ \\
\hline d. $\left.\quad\right|_{\left.\text {xintij-ó })_{\omega} \ldots \sigma\right)_{\iota-\text { phrase }}} ^{\mathbf{i}}$ & & $*$ & & $*$ \\
\hline
\end{tabular}

First, notice that the first two candidates in (125) statisfy the $\iota$-phrase prominence alignment constraint because some later syllable, here shown as $\sigma$, hosts $\iota$-phrase prominence. The winning candidate only violates REALIZE MORPHEME. The reason it violates this constraint is that the bundle of morphological features associated with the status suffix in the input has no phonological realization in the output. The second candidate is bad because the status suffix appears but is not prominent at the $\iota$-phrase, which produces a faithfulness violation. The third candidate violates $\mathrm{ALIGN}_{\iota}$ because not every intonational phrase peak is aligned with the right edge of the intonational phrase. This is clearly not fixable by elimating the final peak. The low ranking STR $\wedge$ STW makes clear that the high level prosodic calculations trump word-level stress placement. Finally, I assume that the status suffixes cannot detach from the verb and move to the intonational phrase boundary, as in example (128).

Xintij- $\otimes$ le ak'.

INFL-eat the chicken

I ate the chicken.

*Xintij-o le ak'. )

*Xintij le ak'-o. )

I remain neutral on what distinguishes affixes and clitics, but however we choose to analyze the difference, we will be able to rule out this candidate because the status suffixes truly are verbal suffixes and are never separated from the root.

While at first pass the distribution of the status suffixes appeared to be non-optimizing, we have just seen that they can be analyzed as cases of affix controlled stress. The descriptive generalization is that the status suffixes appear if and only if they receive intonational phrase prominence, and by placing this prominence requirement in the lexicon, we immediately derive their distribution based on independently needed prominence alignment constraints. While it is true that we need the initial lexical stipulation, the alternative analyses are equally 
stipulative, and they have negative consequences that the affix controlled stress analysis avoids.

\subsubsection{Two alternatives}

Instead of putting prominence specifications in the input, another way to capture the distribution of the phrase-final status suffixes is with morpheme specific alignment constraints (Pater 2000). Such a constraint would force the status suffixes to be aligned with the right edge of the intonational phrase (129). Ranking this constraint over REALIZE MORPHEME will force the suffix to disappear when it cannot be properly aligned.

$$
\text { AlignR(-O/-IK, } \iota \text {-PHRASE) }
$$

Align the right edge of every -ik/-o with the right edge of an $\iota$-phrase.

\begin{tabular}{|c|c|c|}
\hline xintij-o ... & -O, AlignR( $\iota$-PHRASE $)$ & REALIZE MORPH \\
\hline a. $\operatorname{xintij} . ..)_{\iota-\text { phrase }}$ & & * \\
\hline b. $\quad$ xintijo ... $)_{\iota-\text { phrase }}$ & $*$ & \\
\hline
\end{tabular}

Although this analysis works, there are drawbacks. First, we do not understand why it is that the alignment constraint in (129) is active. It is one of only many possible alignment constraints using either edge of any available boundary, yet it generates the same distributional pattern as other cases of optimizing phrase-final allomorphy, like the CV/CVC clitic alternations. Using the alignment constraint in (129), we have no explanation for this. The stress controlled affix analysis has no such problem. We saw that the CV/CVC clitic alternations were sensitive to the placement of intonational phrase prominence, and since the status suffixes have intonational phrase prominence in the input, we immediately draw connections between these two phenomena and expect them to have the same distribution.

A second, related problem is that not only do we stipulate the distributional facts, we derive a generalization about the status suffixes through the accidental interaction of two different constraints. The status suffixes appear if and only if they receive intonational phrase prominence, yet in the alignment analysis, this fact is an accident due to the interaction of two independent alignment constraints. We align the status suffix rightmost in the intonational phrase, and then we align the prominence peak over it. The analysis I propose in terms of affix controlled stress avoids this, and derives the distribution of the status suffixes with independently needed alignment constraints.

The second alternative to consider uses subcategorization frames to capture the distribution of the phrase-final status suffixes. Although there would seem to be little difference between subcategorization and alignment, and while subcategorization approaches suffer from the same problems identified for an analysis with morpheme specific alignment constraints, the two approaches are not equivalent. For example, the type of subcategorization developed by Inkelas (1990) and Zec and Inkelas (1990) yields structures with prosodic adjunction, which produces different predictions. Just as there are good arguments for morpheme specific alignment constraints, there are cases where subcategorization is the stronger analysis, but this is not the case for the phrase-final status suffixes in K'ichee'.

Zec and Inkelas (1990) and Chung (2003) argue for the post-lexical insertion of morphemes that subcategorize for prosodic constituents, and they identify across languages examples of morphemes that subcategorize for prosodic constituents at every level of the prosodic hierarchy. At the center of the proposal is the equation of prosodic subcategoriza- 
tion with prosodic adjunction. A phonological phrase clitic would have the prosodic subcategorization frame in (131), and would apply post-lexically to yield an adjunction structure.

$$
\left((\mathrm{V}-)_{\iota-p h r a s e}-\right)_{\iota-p h r a s e}
$$

One of the strong points of an adjunction analysis of prosodic subcategorization is that such morphemes have a tendency to act as if they are outside the domain they subcategorized for (Zec and Inkelas 1990; Inkelas 1990). Adjunction makes sense of these effects because such morphemes would never be a part of the minimal prosodic constituent where some phonological process happens to take place. But just as these locality effects are an argument for prosodic subcategorization, the behavior of the phrase-final status suffixes suggests that they are not adjoined, and therefore do not have a prosodic subcategorization frame of this sort. First, the phrase-final suffixes necessarily bear the head prominence of the intontational phrase, which goes against the generalization that morphemes that subcategorize for a prosodic constituent are not as integrated into that constituent. The situation is even worse, though, for the phrase-final suffixes. The reason is that they are suffixes, and so they also bear primary word stress for the word containing the verb root they attach to. There is no way to reconcile these two facts. We would need a subcategorization frame that would allow the status suffixes to be a part of the prosodic word, but also adjoined to the intonational phrase.

While we could always use prosodic subcategorization frames without prosodic adjunction, we would lose some of the explanatory power of constraining subcategorization frames in this way, and the resulting analysis would still suffer from the same critiques as the analysis using morpheme specific alignment constraints. The problems for both of these alternative analyses stem from the fact that the phrase-final status suffixes necessarily bear the peak prominence of the intonational phrase. In contrast, the analysis in terms of affix controlled stress takes this to be the primary observation. Across languages there are morphemes that are lexically specified for prominence, and by extending this to prominence in arbitrary prosodic constituents, we are able to understand the appearance of the status suffixes as output optimizing, while capturing their distribution with independently motivated alignment constraints that we already know trigger suppletion.

\subsubsection{Implications for late insertion theories of morphology}

The hallmark of late insertion theories of morphology is that the phonological content of morphemes is separated from their featural content, and is then distributed across the syntaxphonology interface (Anderson 1982, 1992; Embick and Noyer 2001; Halle and Marantz 1993; Hayes 1990, among others). For example, in Distributed Morphology (Halle and Marantz 1993; Embick and Noyer 2001, inter alia), morphological feature bundles get associated with their phonological forms along the PF branch at the point when the operation Vocabulary Insertion applies. Global parallel approaches to morphophonology, like the OT account developed in this work, are compatible with the hypothesis that morphemes are only associated with their phonological outputs after syntax. In this account, the relevant aspects of Vocabulary Insertion, in the parlance of Distributed Morphology, are modeled by the constraint REALIZE MORPHEME and the fact that inputs can include sets of allomorphs. The constraint REALIZE MORPHEME models the pressure to associate a morpheme (or feature bundle) in the input with a phonological exponent in the output. Since this constraint is violable, high ranking constraints can force a morpheme to go unassociated with phonological content, as with the K'ichee' status suffixes. The fact that inputs allow sets of morphemes 
permits an account of the conditionalized vocabulary insertion we see with allomorphy, exemplified in this paper by the clitic alternations. The same feature bundle can be associated with different phonological exponents depending on the phonological environment in which it occurs.

Since OT is not derivational, calculating how feature bundles are associated with phonological outputs happens in parallel with the rest of the phonology. The result is that morphological alternations can be conditioned by many phonological factors, including high level prosodic structure, as we have shown here. ${ }^{30}$ The fact that prosodic information is available to condition morphological alternations in OT approaches to morphophonology does not extend to other theories of morphology. For example, prosody is built late in most strands of Distributed Morphology, as in (Embick and Noyer 2001), whose model is presented in the figure below. ${ }^{31}$

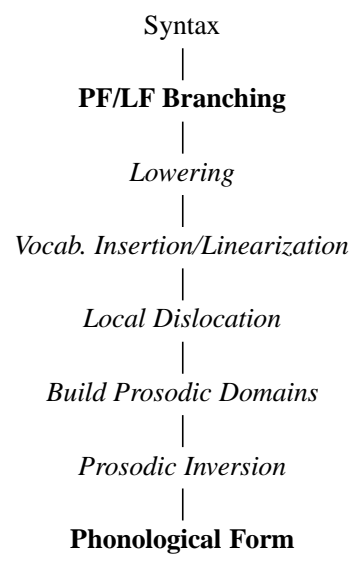

Fig. 2 Embick and Noyer (2001)'s Model of the PF Branch of the Grammar

The problem with the model in figure 4.3.2 is that vocabulary insertion happens before prosody domains are built. The result is that Vocabulary Insertion should not be able to be sensitive headedness in high level prosodic structure, which is needed to account for the distribution of status suffixes and clitic allomorphy in K'ichee'.

The primary result of this work is that the model in fig. 4.3.2 should be replaced with one where at least some prosodic structure is built before vocabulary insertion (See Ackema and Neeleman (2003) for independent arguments to this effect). ${ }^{32}$ This would allow Vocabulary Insertion to be sensitive to prosodic structure. For example, the two status suffixes

\footnotetext{
${ }^{30}$ Embick (2010) argues that this property of global parallel approaches to morphology is a defect. The reason is that allomorphy should be able to be conditioned by non-local phonological enviornments that do not, in fact, seem to condition allomorphy.

${ }^{31}$ Other authors argue that prosody is irrelevant for morphosyntax (Pak 2008; Embick 2010).

${ }^{32}$ As suggested by one reviewer, we should also entertain the possibility that vocabulary insertion happens before prosodic structure is built, but that further operations could delete or alter morphemes to achieve the effect we see in K'ichee'. On one hand, if these are phonological operations like those proposed in this paper, then the effects of the morphosyntactic Vocabulary Insertion are completely masked. We would have two independent late insertion morphologies, each placing constraints on how feature bundles are associated with phonological exponents. On the other hand, if we allow further morphological operations to undo Vocabulary Insertion, we would be allowing Duke-of-York morphological derivations. While this does not mean that such an analysis is wrong, it is less preferred on theoretical grounds.
} 
considered most prominently in this work could be associated with the following vocabulary items.

$$
\begin{aligned}
& \left.\mathrm{T}_{\text {intrans }}^{\circ}\right)_{\iota \mathrm{P}} \leftrightarrow / \text {-ik/ } \\
& \left.\mathrm{T}_{\text {trans }}^{\circ}\right)_{\iota \mathrm{P}} \leftrightarrow /-\mathbf{o} / \\
& \text { Elsewhere } \leftrightarrow \emptyset
\end{aligned}
$$

Here we assume that the status suffixes are exponents of the $\mathrm{T}^{\circ}$ head, which comes in two flavors depending on whether $\mathrm{T}^{\circ}$ selects for a transitive or intransitive verb phrase. Putting the status suffixes in $\mathrm{T}^{\circ}$ is further supported by the fact that beyond transitivity, status suffixes are conditioned by the TAM class of the clause. The result of the vocabulary items in (132) to (134) is that the status suffixes will only be inserted when adjacent to an intonational phrase boundary. Otherwise, the elsewhere morpheme will be inserted, which is empty in this case. While this analysis suffers from the same criticisms as the prosodic subcategorization account considered above, it illustrates an important larger point. To account for the phrase-final morphological alternations in K'ichee', the operations linking morphological feature bundles with phonological exponents must have access to prosodic information. This is immediately satisfied in an OT approach by its global parallel evaluation procedure. For derivational approaches to morphology, the implication is that at least some prosodic structure is built before vocabulary insertion. An important area of future work would be to determine how much prosody is built before vocabulary insertion and whether later processes can alter this prosodic structure.

\section{Conclusions}

This paper gives a comprehensive account of K'ichee' phrase-final allomorphy, and in doing so, proposes analyses of areas of K'ichee' phonology as diverse as the syntax-prosody mapping and the stress system. The reason is that in K'ichee', gross syntactic structure (the distribution of clauses and head-argument relations) governs the distribution of intonational phrase boundaries, which in turn affects stress placement, which ultimately drives morphological alterations. The important fact is that $\mathrm{K}$ 'ichee' independently requires a prominence peak to be aligned rightmost in the intonational phrase. For clitic allomorphy, this means the CVC form appears when it can bear phrase-final stress, and otherwise the CV form is chosen as an instance of TETU. Similarly, the status suffixes can only appear when $\iota$-phrase prominence alignment permits because they are lexically specified for $\iota$-phrase prominence, which is an extension of the idea that languages can have morphologically controlled stress.

While this work allows us to understand K'ichee'-specific phonomena in detail, it also opens up a way to larger theoretical questions about the syntax-phonology-morphology interface. First, the analysis supports theories where morphology is done in the phonology. We saw that the distribution of phrase-final morphological alternations is prosodic in nature, where prosodic structure is determined post-syntactically. This leads to another conclusion, namely, that the phonological content of morphemes is only inserted after syntax. The idea is already implicit in the definition of constraints like REALIZE MORPHEME, which requires feature bundles (morphemes) to have phonological exponents in the output. By ranking REALIZE MORPHEME low, we model conditionalized vocabulary insertion as follows: Associate a feature bundle in the syntax with phonetic content in the output of phonology only if it is phonologically optimal to do so. Since phonology can decide whether or not a morpheme is phonologically realized, there is no reason to put phonological content in the syntax. An 
even clearer argument for the late insertion of morphemes comes from the behavior of the phrase-final clitic alternations. In this case, we cannot put the phonological content of the morphemes in question in the syntax because we cannot know what shape they will take until the calculation of stress placement, which must be kept separate from syntax for theoretical and empirical reasons.

While the late insertion of morphemes is not new, this work is innovative in that it establishes a new lower bound for when insertion takes place. Both cases of phrase-final morphological alternations discussed here are sensitive to prominence peaks at the level of the intonational phrase. This means that the late insertion of phonological content into morphemes cannot happen until intonational phrases have been constructed. Other researchers have argued this to be true (Chung 2003; Hayes 1990), but K'ichee' provides the strongest evidence for this position. The reason is that the other cases of morphology sensitive to intonational phrase boundaries involve the distribution of clitics, and not suppletion (Aissen 1992; Chung 2003; Zec and Inkelas 1990). When dealing with clitics, there is always the possibility that they are inserted early and only move as more structure is built cyclically (either through PF movement or alignment constraints). There is no such option with the two phenomena considered in this work. For the phrase-final status suffixes, the decision about whether they appear or not must be postponed until intonational phrases are built. In theories the employ late insertion, this means that, barring a Duke-of-York derivation, these suffixes must be inserted after the construction of intonational phrases. Similarly, we cannot choose which suppletive clitic allomorph to insert until that same point. In this way, K'ichee' phrase-final morphological alternations provide clear evidence that morphemes can be inserted as late as the construction of the highest levels of the prosodic hierarchy, which supports earlier analyses that argue for this to be the case.

Finally, while the analysis does not settle the question of whether prosodically conditioned morphological alternations should be handled in the OT phonology or in a derivational approach like Distributed Morphology (Halle and Marantz 1993; Embick and Noyer 2001; Embick 2010, inter alia), this work places clear empirical boundaries on what a derivational account would look like. Most importantly, it must associate feature bundles with phonological exponents after parsing the syntax into intonational phrases, supporting a view of the morphological component like that of Ackema and Neeleman (2003). Moreover, it should capture the connections between phrase-final morphological alternations and the distribution of prominence peaks at various levels of prosodic structure.

\footnotetext{
${ }^{32}$ Above all I am indebited to Jenifer Estefani Vicente Lopez and the Can Pixab'aj family for their judgements. I am also greatly indebited to Telma Can Pixab'aj for her judgements and insights into the phenomena under discussion. Armin Mester deserves great thanks for all his help. I also need to thank Judith Aissen, Scott AnderBois, Ryan Bennett, Andrew Dowd, Nora England, Junko Itô, B'alam Mateo Toledo, Andrew Nevins, Jeremy O'Brien, Dave Teeple, and Matt Tucker for many productive discussions about these data and the analysis within. Four NLLT reviewers deserve credit for their constructive comments that improved this paper. Finally, I need to thank the CrISP Research Group at UCSC and an audience at NELS 40 for their input. That being said, the usual disclaimers apply. This work was supported by a travel grant from the UCSC Institute for Humanities Research, a grant from the UCSC linguistics department, and the Tanya Honig Fund for Linguistics Graduate Students.
} 


\section{References}

Ackema, Peter, and Ad Neeleman. 2003. Context-sensitive spell-out. Natural Language \& Linguistic Theory 21: 681-735.

Aissen, Judith. 1992. Topic and focus in Mayan. Language 68: 43-80.

Aissen, Judith. 1996. Pied-piping, abstract agreement, and functional projections in Tzotzil. Natural Language \& Linguistic Theory 14: 447-491.

Alderete, John. 1999. Morphologically governed accent in optimality theory. PhD Dissertation, The University of Massachusetts, Amherst.

AnderBois, Scott. 2008. Strong positions and laryngeal features in Yukatek Maya. In The Proceedings of NELS 39, eds. Kevin Mullin Suzi Lima and Brian Smith. Amherst, MA: GLSA.

Anderson, Stephen. 1982. Where's morphology? Linguistic Inquiry 13: 571-612.

Anderson, Stephen R. 1992. A-morphous morphology, volume 62. Cambridge: Cambridge University Press.

Anttila, Arto. 2008. Phonological constraints on constituent ordering. In The Proceedings from WCCFL 26, eds. Charles B. Chang and Hannah Haynie. Sommerville, MA: Cascadilla Press.

Campbell, Lyle. 1977. Quichean linguistic prehistory. Berkeley, CA: Univerity of California Press.

Can Pixabaj, Telma. 2004. La topicalización en K'ichee': Una perspectiva discursiva. Tésis de Licenciatura, Universidad Rafael Landívar, Guatemala, C.A.

Can Pixabaj, Telma. 2010. Predicación secundaria en K'ichee': Una construcción restringida. In La predicación secundaria en lenguas de mesoamérica, eds. Judith Aissen and Roberto Zavala. Mexico City: CIESAS.

Chomsky, Noam. 1965. Aspects of the theory of syntax. Cambridge, Massachusetts: MIT Press.

Chomsky, Noam, and Morris Halle. 1968. The sound pattern of English. New York: Harper \& Row Publishers.

Chung, Sandra. 2003. The syntax and prosody of weak pronouns in Chamorro. Linguistic Inquiry 34: 547-599.

Coon, Jessica. 2009. Interrogative possessors and the problem with pied-piping in Chol. Linguistic Inquiry 40: 165-175.

Dresher, Bezalel Elan. 1994. The prosodic basis of the Tiberian Hebrew system of accents. Language 70: 1-52.

Edmonds, Joseph. 1970. Root and structure-preserving transformations. PhD Dissertation, MIT, Cambridge, Massachusetts.

Embick, David. 2010. Localism versus globalism in morphology and phonology. Cambridge, Massachusetts: MIT Press.

Embick, David, and Rolf Noyer. 2001. Movement operations after syntax. Linguistic Inquiry 32: 555-595.

Grimshaw, Jane. 1979. Complement selection and the lexicon. Linguistic Inquiry 10: 279326.

Grimshaw, Jane. 1981. Form, function, and the language acquisition device. In The logical problem of language acquisition, eds. C.L. Baker and John McCarthy, 165-182. Cambridge, Massachusetts: The MIT Press.

Halle, Morris, and William Idsardi. 1994. General properties of stress and metrical structure. In Language Computations: DIMACS Workshop on Human Language, March 20 22, 1992, ed. Eric Sven Ristad, 37-70. Providence, RI: American Mathematical Society. 
Halle, Morris, and Alec Marantz. 1993. Distributed morphology and the pieces of inflection. In The view from building 20, eds. Kenneth Hale and Samuel Jay Keyser, 111-176. Cambridge, Massachusetts: MIT Press.

Hayes, Bruce. 1990. Precompiled phrasal phonology. In The phonology-syntax connection, eds. Sharon Inkelas and Draga Zec, 85-108. Chicago: University of Chicago Press.

Hayes, Bruce. 1995. Metrical stress theory: Principles and case studies. Chicago, IL: University of Chicago Press.

Hyde, Brett. 2007. Issues in Banawá prosody: Onset sensitivity, minimal words, and syllable integrity. Linguistic Inquiry 38: 239-285.

Inkelas, Sharon. 1990. Prosodic constituency in the lexicon. Garland: New York.

Ito, Junko, and Armin Mester. 2006. Prosodic adjunction in Japanese compounds. In FAJL 4, eds. Yoichi Miyamoto and Masao Ochi, 197-213. MIT working papers in linguistics.

Kager, Rene. 1999. Optimality theory. Cambridge: Cambridge University Press.

Kaufman, Terrence. 1990. Algunos rasgos estructurales de los idiomas mayances con referencia especial al K'iche'. In Lecturas sobre la lingüística maya, eds. Nora England and Stephen Elliott, 59-114. La Antigua Guatemala: Centro de Investigaciones Regionales de Mesoamérica.

Larsen, Thomas. 1988. Manifestations of ergativity in Quiché grammar. PhD Dissertation, University of California, Berkeley.

Liberman, Mark, and Alan Prince. 1977. On stress and linguistic rhythm. Linguistic inquiry 249-336.

López Ixcoy, Candelaria Dominga. 1997. Ri ukemiik ri K'ichee' chii': Gramática K'ichee'. Guatemala City: Cholsamaj.

Mascaró, Joan. 2007. External allomorphy and lexical representation. Linguistic Inquiry 4.

McCarthy, John, and Alan Prince. 1986/1996. Prosodic morphology. Technical Report 32, Rutgers University Center for Cognitive Science, 1996.

McCarthy, John, and Alan Prince. 1993. Generalized alignment. Yearbook of morphology 1993: 79-153.

Mester, R. Armin. 1994. The quantitative trochee in Latin. Natural Language and Linguistic Theory 12: 1-62.

Mondloch, James. 1978. Basic quiche grammar. Institute for Latin American Studies, SUNY, Albany.

Nespor, Marina, and Irene Vogel. 1986. Prosodic phonology. Dordrecht, Holland: Foris.

Pak, Marjorie. 2008. The postsyntactic derivation and its phonological reflexes. PhD Dissertation, University of Pennsylvania, Philadelphia, PA.

Paster, Mary. 2006. Phonological conditions on affixation. PhD Dissertation, University of California, Berkeley.

Pater, Joe. 2000. Nonuniformity in english stress: the role of ranked and lexically specific constraints. Phonology 17: 384-402.

Potts, Christopher. 2002. The syntax and semantics of as-parentheticals. Natural Language and Linguistic Theory 20: 623-689.

Prince, Alan, and Paul Smolensky. 1993. Optimality theory: Constraint interaction in generative grammar. Ms. Rutgers University, New Brunswick and University of Colorado, Boulder.

Richards, Michael. 2003. Atlas lingüisticó de Guatemala. Guatemala City: Universidad Rafael Landívar.

Selkirk, Elisabeth. 1995. The handbook of phonological theory, chapter Sentence prosody: intonation, stress and phrasing. London: Blackwell. 
Selkirk, Elisabeth. 2005. Comments on intonational phrases in english. In Prosodies: Selected papers from the phonetics and phonology in Iberia conference, 2003, eds. Marina Vigário Sónia Frota and Jaão Freitas, 11-58. Berlin: Mouton de Gruyter.

Selkirk, Elisabeth O. 1980. The role of prosodic categories in English word stress. Linguistic Inquiry 11: 563-605.

Selkirk, Elisabeth O. 1984. Phonology and syntax : the relation between sound and structure. Cambridge, Massachusetts: MIT Press.

Steedman, Mark. 2000. Information structure and syntax-phonology interface. Linguistic Inquiry 31: 649-689.

Truckenbrodt, Hubert. 1999. On the relation betwen syntactic phrases and phonological phrases. Linguistic Inquiry 30: 219-255.

Wagner, Michael. 2005. Prosody and recursion. PhD Dissertation, MIT.

Watson, Duane, and Edward Gibson. 2004. Making sense of the sense unit condition. Linguistic Inquiry 35: 508-517.

Watson, Duane, and Edward Gibson. 2005. Intonational phrasing and constituency in language production and comprehension. Studia Linguistica 59: 279-300.

Werle, Adam. 2004. Enclisis and proclisis in Bosnian/Serbian/Croatian. In Proceedings of the West Coast Conference on Formal Linguistics, eds. Benjamin Schmeiser Ann Kelleher, Angelo Rodríguez and Vineeta Chand, 801-814. Sommerville, MA: Cascadilla Press.

Zec, Draga, and Sharon Inkelas. 1990. Prosodically constrained syntax. In The phonologysyntax connection, eds. Sharon Inkelas and Draga Zec, 365-378. Chicago: University of Chicago Press.

Zoll, Cheryl. 2004. Positional asymmetries and licensing in optimality theory, 343-364. Oxford: Blackwell Publishing, Ltd.

Zwicky, Arnold. 1985. Clitics and particles. Language 61: 283-305.

Zwicky, Arnold M., and Geoffrey K. Pullum. 1983. Phonology in syntax: the Somali optional agreement rule. Natural Language and Linguistic Theory 1: 385-402.

Zwicky, Arnold M., and Geoffrey K. Pullum. 1988. The syntax-phonology interface, volume 1, 255-280. Cambridge: Cambridge University Press. 